Article

\title{
Proteomics Analysis Reveals that Warburg Effect along with Modification in Lipid Metabolism Improves In Vitro Embryo Development under Low Oxygen
}

\author{
Qaisar Shahzad ${ }^{1}{ }^{1}$, Liping Pu ${ }^{1}$, Armughan Ahmed Wadood ${ }^{1}$, Muhammad Waqas ${ }^{1}$, Long Xie ${ }^{1}$, \\ Chandra Shekhar Pareek ${ }^{2,3}{ }^{-\infty}$, Huiyan $\mathrm{Xu}^{1}{ }^{1}$, Xianwei Liang ${ }^{4}$ and Yangqing $\mathrm{Lu}{ }^{1, *}$ \\ 1 State Key Laboratory for Conservation and Utilization of Subtropical Agro-bioresources, College of Animal \\ Science and Technology, Guangxi University, Nanning, Guangxi 530000, China; \\ raoqaisarshahzad@gmail.com (Q.S.); 18775352516@163.com (L.P.); armughanwadood@gmail.com (A.A.W.); \\ waqas_sk@yahoo.com (M.W.); mrchildren77582580@163.com (L.X.); xuhuiyan412@vip.163.com (H.X.) \\ 2 Institute of Veterinary Medicine, Faculty of Biological and Veterinary Sciences, Nicolaus Copernicus \\ University, 87-100 Torun, Poland; pareekcs@umk.pl \\ 3 Division of Functional genomics in biological and biomedical research, Centre for Modern Interdisciplinary \\ Technologies, Nicolaus Copernicus University, 87-100 Torun, Poland \\ 4 Guangxi Key Laboratory of Buffalo Genetics and Breeding, Buffalo Research Institute, Chinese 10 Academy \\ of Agriculture Science, Nanning 530001, China; liangbri@126.com \\ * Correspondence: luyangqing@126.com; Tel.: +86-13768580206
}

Received: 18 February 2020; Accepted: 12 March 2020; Published: 14 March 2020

\begin{abstract}
The molecular mechanism regulating embryo development under reduced oxygen tension remains elusive. This study aimed to identify the molecular mechanism impacting embryo development under low oxygen conditions. Buffalo embryos were cultured under $5 \%$ or $20 \%$ oxygen and were evaluated according to their morphological parameters related to embryo development. The protein profiles of these embryos were compared using iTRAQ-based quantitative proteomics. Physiological $\mathrm{O}_{2}(5 \%)$ significantly promoted blastocyst yield, hatching rate, embryo quality and cell count as compared to atmospheric $\mathrm{O}_{2}(20 \%)$. The embryos in the $5 \% \mathrm{O}_{2}$ group had an improved hatching rate of cryopreserved blastocysts post-warming $(p<0.05)$. Comparative proteome profiles of hatched blastocysts cultured under $5 \%$ vs. $20 \% \mathrm{O}_{2}$ levels identified 43 differentially expressed proteins (DEPs). Functional analysis indicated that DEPs were mainly associated with glycolysis, fatty acid degradation, inositol phosphate metabolism and terpenoid backbone synthesis. Our results suggest that embryos under physiological oxygen had greater developmental potential due to the pronounced Warburg Effect (aerobic glycolysis). Moreover, our proteomic data suggested that higher lipid degradation, an elevated cholesterol level and a higher unsaturated to saturated fatty acid ratio might be involved in the better cryo-survival ability reported in embryos cultured under low oxygen. These data provide new information on the early embryo protein repertoire and general molecular mechanisms of embryo development under varying oxygen levels.
\end{abstract}

Keywords: buffalo; embryo; oxygen; proteome; warburg effect

\section{Introduction}

Buffalo is a major source of milk, meat and other dairy products, which boosts the economy of various developing countries. The importance of this species is evidenced by the fact that it fulfils almost $13 \%$ of the world's milk demand [1]. Due to the increasing world population, there is a dire need and a huge demand to enhance livestock productivity. Therefore, assisted reproductive techniques 
(ART) are being applied to improve livestock genetics [2]. In particular, in vitro embryo production (IVEP) has been used to strengthen knowledge regarding oocyte and embryonic growth [3], producing low-cost embryos for basic research, the propagation of elite female genetics, in combination with sex sorted sperm technology for generation of sexed embryos [4], and the application of embryo technologies like nuclear transfer and transgenesis.

The IVEP system has significantly improved over the past few decades, resulting in higher blastocyst yield, pregnancy development and birth rate in various mammalian species [5-8]. Besides the improvement, it is still considered an inefficient technique because only $5 \%$ of matured oocytes lead to live birth [9]. The major issue impeding embryonic development in vitro is the oxidative stress. Indeed, in vitro, higher atmospheric oxygen tension $(20 \%)$ increased the generation of ROS compared to that in the female reproductive tract $(2 \%-8 \%)$ [10]. ROS production is further accelerated through the metabolism of spermatozoa, oocytes and the embryo as well as during the thawing of media. These ROS can diffuse through the cell membrane and alter cellular molecules like proteins, lipids and nucleic acids. There are several consequences of ROS diffusion into cells, such as mitochondrial damage, ATP depletion, DNA damage, membrane disruption due to lipid peroxidation, embryo developmental block and apoptosis [11].

During in vivo fertilization, the embryo is protected by oxygen scavengers present in oviductal and follicular fluid, but in vitro these are absent. There are several strategies to reduce oxidative stress during the process of IVEP, including the reduction in oxygen to a physiological level [12] and the addition of antioxidants in culture media [13]. Discrepancies are reported regarding oxygen tension during IVEP. Several studies showed that there is no effect of oxygen on embryonic development $[14,15]$, while others reported higher blastocyst rate or lower apoptosis in lowered oxygen tension $(5 \%-7 \%)$ in several species [16-18]. It is therefore important to elucidate whether regulating oxygen tension can be a means to improve IVEP.

The efficiency of IVEP can be enhanced through understanding the molecular mechanism of embryo development. Many approaches have greatly expanded our understanding of the molecular mechanism associated with embryo development, such as transcriptomics, epigenomics, single cell and microcell sequencing [19-25]. However, proteomics might provide us with a direct insight into the molecular mechanism governing embryo development, as proteins are the executors of most of the developmental programs. Moreover, proteomic analysis has been conducted to comprehend the mechanism of oocyte and embryo development in various species including buffalo [26,27], cows [28-30], mice [31-36] and pigs [37-40]. However, there is no study available determining the role of oxygen tension on in vitro embryo development at the proteome level. In the present study, we have cultured the buffalo embryos under atmospheric oxygen (20\%) or physiological oxygen (5\%) and evaluated the morphological parameters of embryo development. Simultaneously, we have analyzed these embryos for alterations in the proteome at the hatched blastocyst stage by using an iTRAQ-based mass spectrometry technique [41].

\section{Results}

\subsection{Evaluation of the Effect of Oxygen Tension (5\% vs. 20\%) on Morphological Parameters of Embryo Development}

\subsubsection{Cleavage, Blastocyst, Hatching Rate and Developmental Kinetics}

The cleavage and blastocyst rate are the number of cleaved embryos and blastocysts normalized to the total number of oocytes (inseminated), respectively. The hatching rate is the number of hatched blastocysts normalized to the total number of blastocysts. The analysis of morphological parameters of embryo production indicated that $5 \% \mathrm{O}_{2}$ had no effect on cleavage rate $(50.46 \pm 1.76$ vs $51.1 \pm 2.53)$ as compared to atmospheric oxygen. However, $5 \%$ significantly $(p<0.05)$ improved blastocyst rate $(34.08 \pm 2.40 \mathrm{vs} 24.28 \pm 0.51)$ as well as increased hatching rate $(83.67 \pm 2.14 \mathrm{vs} 68.7 \pm 1.38)$ as compared to $20 \% \mathrm{O}_{2}$ (Figure 1). 


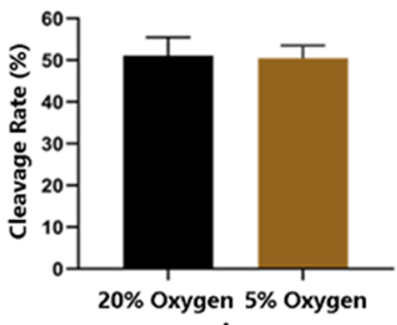

A

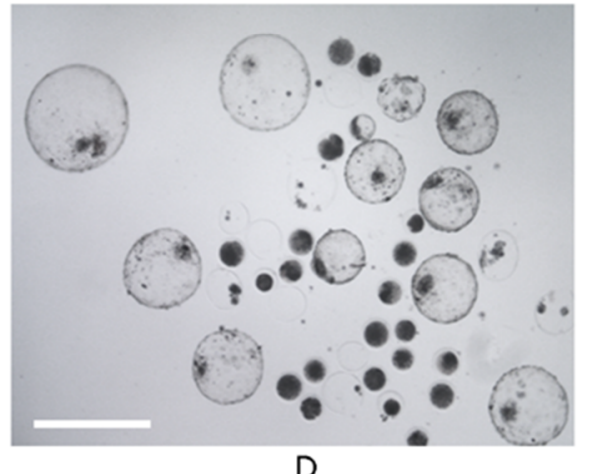

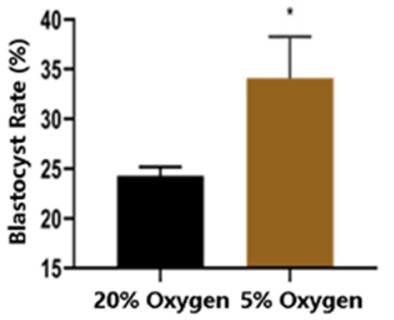

B

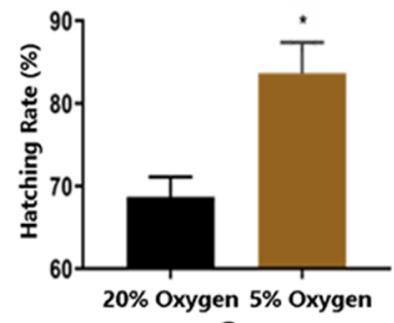

C

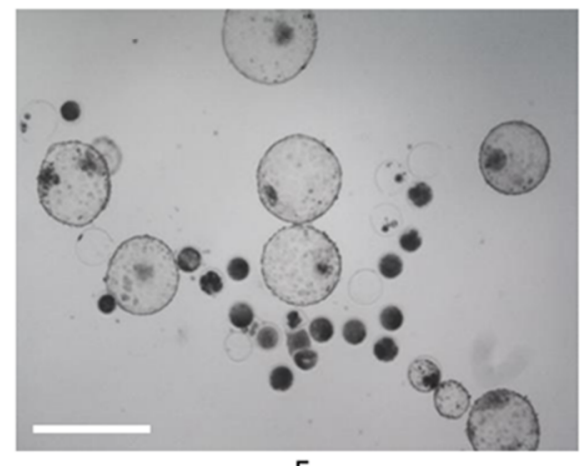

$E$

Figure 1. Effect of varying oxygen levels (20\% vs. $5 \%$ ) on embryo development. All the experiments were repeated three times. Embryos were cultured in $20 \%(n=180)$ or $5 \%(n=178)$ oxygen and assessed for cleavage on day 2 of culture. Oxygen did not influence the cleavage rate of embryos (A). Culture under $5 \%$ oxygen $(n=567)$ improved the proportionate of the embryos developing to the blastocyst stage (B) and hatched blastocyst stage $(\mathbf{C})$ as compared to $20 \%$ oxygen $(n=576)$. The blastocyst and hatching rate were evaluated on day 7 of embryo development. Representative photographs of embryos cultured in $5 \%$ oxygen (D) and $20 \%$ oxygen (E). The images (1D and $1 \mathrm{E}$ ) were captured with microscope (50i; Nikon, Japan) at $100 \times$ resolution. Asterisk $\left(^{*}\right)$ indicates the statistical difference $(p<0.05)$ between the groups.

The developmental kinetics of embryos were evaluated at day 5, 6, 7 and 8 of culture by assessing developmental stages of embryos. The physiological $\mathrm{O}_{2}$ group had a more significant number of embryos at advanced stages on the particular day of development as compared to the atmospheric $\mathrm{O}_{2}$ group (Figure 2). 
$20 \%$ Oxygen

\section{$5 \%$ Oxygen}
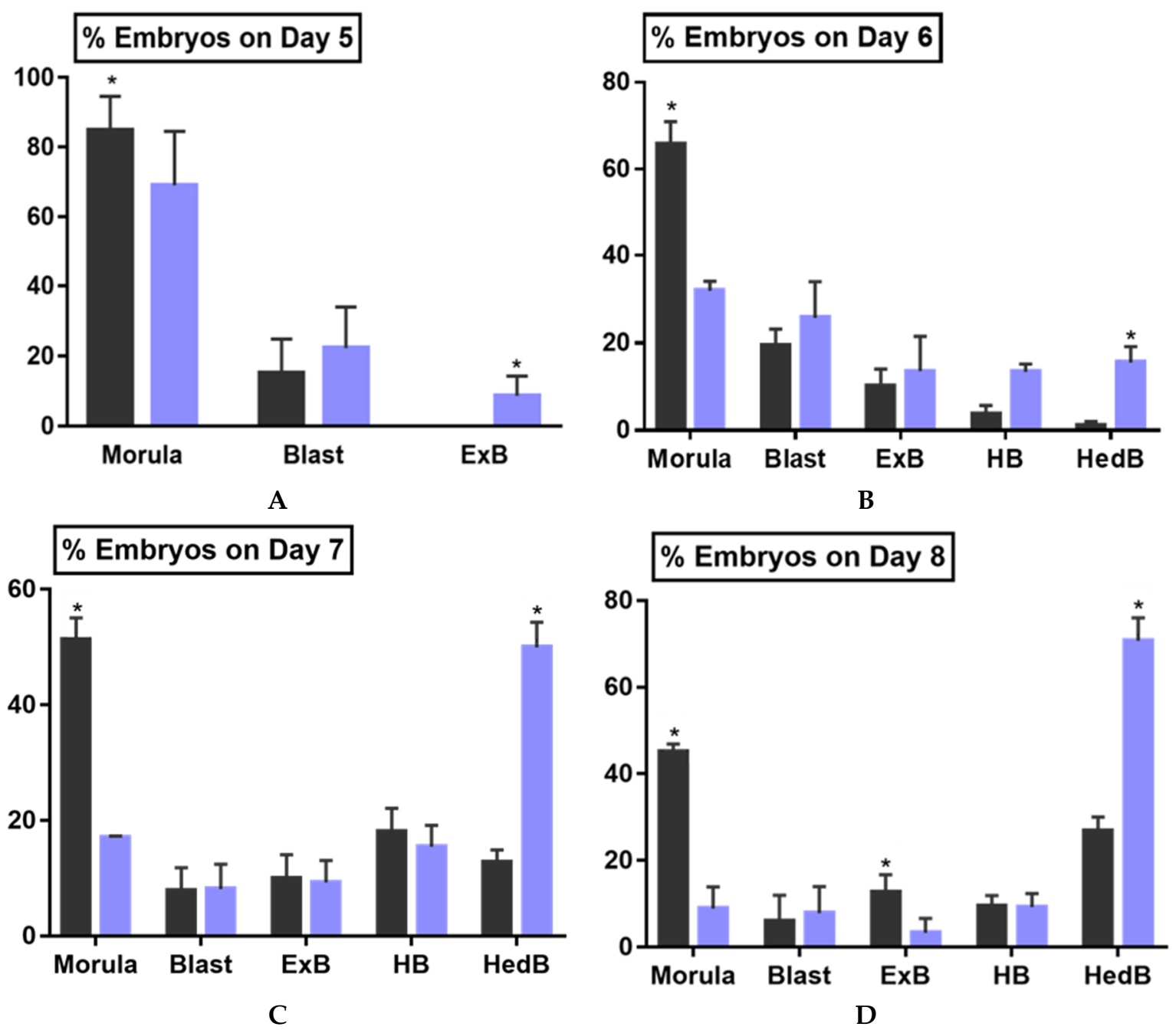

Figure 2. Effect of varying oxygen levels ( $20 \%$ vs. $5 \%$ ) on developmental kinetics of buffalo embryos. All the experiments were replicated three times. The percentage of embryos at different developmental stages, morula, blastocyst (Blast), expanded blastocyst (ExB), hatching blastocyst (HB), hatched blastocyst (HedB), on day 5, 6, 7 and 8 was evaluated. There was a significantly higher rate of embryos at advanced developmental stages in $5 \%$ oxygen as compared to $20 \%$ oxygen. Fifty-nine and 53 embryos from $20 \%$ and $5 \%$ oxygen group, respectively, were evaluated on day 5 (A). Sixty-four embryos from each group were evaluated on day 6 (B). Sixty-three and 64 embryos from $20 \%$ and $5 \%$ oxygen group respectively, were evaluated on day 7 (C). Sixty-nine and 60 embryos from $20 \%$ and $5 \%$ oxygen group, respectively, were evaluated on day 8 (D). Values represent mean $\% \pm$ S.E.M. Asterisk $\left(^{*}\right)$ indicates the statistical difference, $p<0.05$.

\subsubsection{Cell Count}

The cell count was determined by staining the hatched blastocysts with Hoechst 33342 . These morphological findings of embryo development were further reinforced by the cell count evaluation, as shown in Figure 3, which revealed that embryos cultured under $5 \% \mathrm{O}_{2}$ had significantly $(p<0.05)$ higher cell counts as compared to the embryos developed under $20 \% \mathrm{O}_{2}$ (Table 1). 


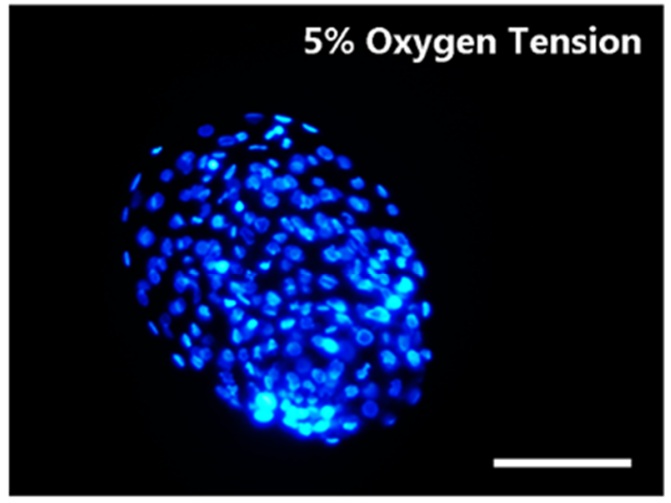

A

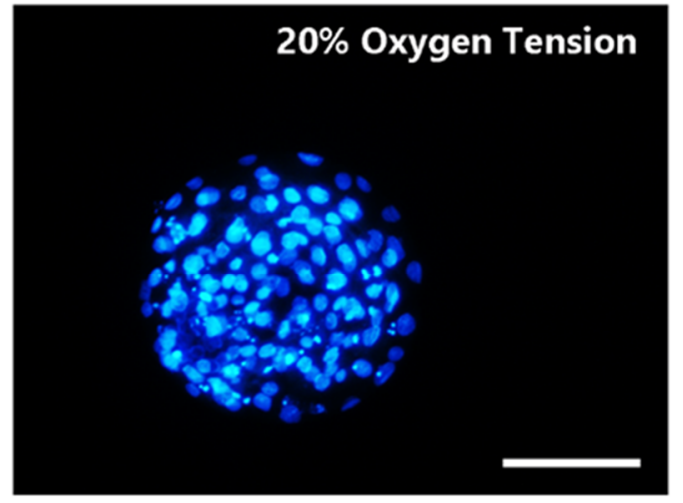

B

Figure 3. Hatched blastocysts stained with Hoechst 33342 to determine the total cell count. Blastocysts were cultured under $5 \%$ (A) and 20\% (B) oxygen tension. The images were captured with microscope (50i; Nikon, Japan) at $200 \times$ resolution.

Table 1. Cell count of embryos cultured in 5\% and 20\% Oxygen.

\begin{tabular}{ccc}
\hline Parameters. & N & Cell Count (Mean \pm S.E.M) \\
\hline $5 \%$ Oxygen & 15 & $151.36 \pm 2.70$ \\
\hline $20 \%$ Oxygen & 15 & $89.18 \pm 2.60 *$ \\
\hline
\end{tabular}

Asterisk $\left(^{*}\right)$ indicates the significant difference $(p<0.05)$ between the groups.

\subsubsection{Embryo Quality Scoring}

The embryo quality scoring system was based on the definitions presented in the manual of the European Society of Human Reproduction and Embryology (see Materials and Methods section). Embryos were scored from score 1 (less advanced embryos) to score 6 (hatched blastocysts). The results based on the embryo quality scoring suggest that significantly $(p<0.05)$ better quality of embryos are produced under low oxygen as compared to atmospheric oxygen culture (Figure 4). The physiological oxygen group had a lower proportion of low score embryos and a higher proportion of the high score embryos in comparison with the $20 \% \mathrm{O}_{2}$ group.

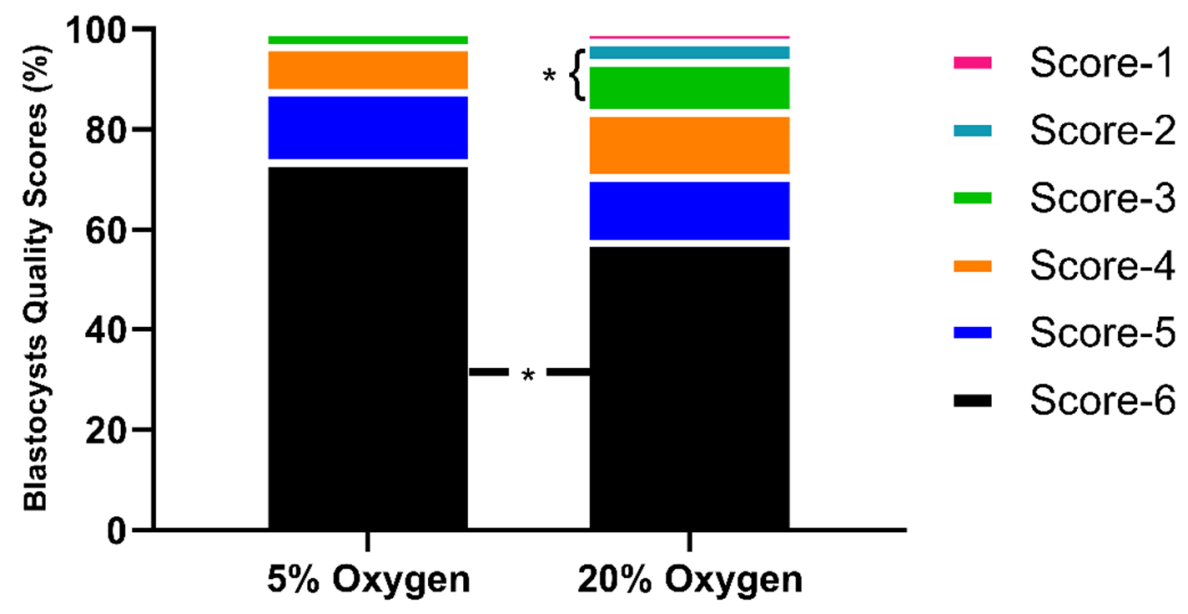

Figure 4. Embryo quality scoring. Physiological oxygen improved the quality of blastocysts, as indicated by lower percentage of low score blastocysts and higher proportionate of high score blastocysts. Asterisk $\left.{ }^{*}\right)$ indicates the significant difference $(p<0.05)$ between the groups. 


\subsubsection{Cryo-Survival Potential of Vitrified Blastocysts}

The cryo-survival ability of vitrified blastocysts was determined by evaluating hatching rate post-warming (Table 2). The results show that reduced oxygen embryo culture plays an essential role in enhancing the cryo-survival ability of the blastocysts, as revealed by significantly higher hatching rate (post-warming) under low oxygen embryo culture in comparison to atmospheric oxygen culture $(82.67 \% \pm 4.44 \%$ vs. $60.69 \% \pm 1.80 \%)$.

Table 2. Post-warming hatching rate of the blastocysts produced under different levels of oxygen (5\% and $20 \%)$.

\begin{tabular}{ccc}
\hline Parameters & N & Hatching Rate (Mean \pm S.E.M) \\
\hline $5 \%$ Oxygen & 42 & $82.67 \pm 4.44$ \\
\hline $20 \%$ Oxygen & 38 & $60.69 \pm 1.80 *$ \\
\hline
\end{tabular}

Asterisk $\left.{ }^{*}\right)$ indicates the significant difference $(p<0.05)$ between the groups.

\subsection{Proteomic Analysis of Embryos Cultured under $5 \%$ or $20 \%$ Oxygen Tension}

The precision of proteomic quantification was evaluated by Pearson's correlation coefficient and coefficient of variance. The stability of the proteomic analysis was confirmed by a significant correlation between the three technical replicates (Figure 5A). The correlation coefficient was more than 0.60 , which represents a good correlation among the replicates of each group. Figure $5 \mathrm{~B}$ shows the percentages of proteins with a mean $\mathrm{CV}<10 \%, 10 \% \leq \mathrm{CV}<20 \%$, and $\mathrm{CV} \geq 20 \%$. Overall, more than $90 \%$ of proteins had less than $10 \%$ coefficient of variance. Proteins with $>20 \%$ coefficient of variance were less than $1 \%$ in the dataset, confirming the reliability of the analysis. A total of 954 proteins were identified in embryos cultured at $20 \%$ or $5 \%$ oxygen, and 566 proteins were found to be shared among all the replicates (Figure $6 \mathrm{~A})$. The differential expression analysis $\left(\log _{2} \mathrm{FC}\left[\frac{5 \%}{20 \%}\right]>20 \%, p<0.05\right)$ showed 25 upregulated and 18 downregulated proteins (Figures 5 and 6, Supplementary Table S1). Out of 43 differentially expressed proteins (DEPs), five were uncharacterized, which have been omitted from the heatmap (Figure 6B). The DEPs were mainly associated with metabolic pathways such as aerobic glycolysis, lipid degradation, terpenoid backbone synthesis and inositol phosphate metabolism.

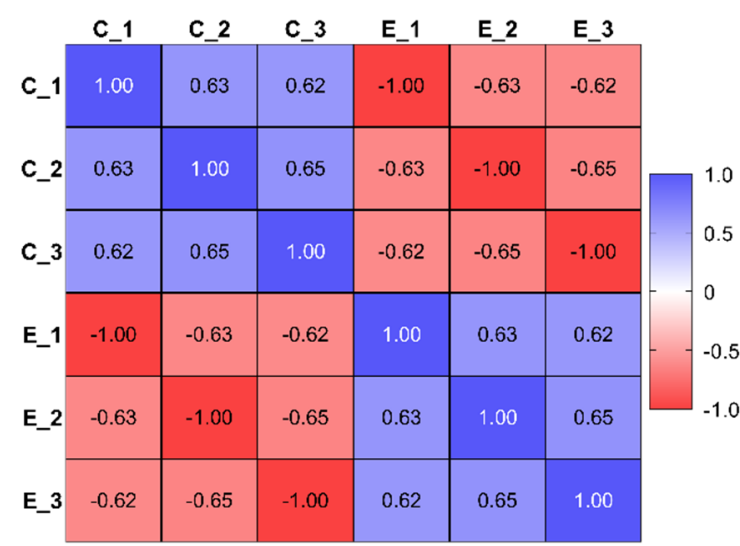

A

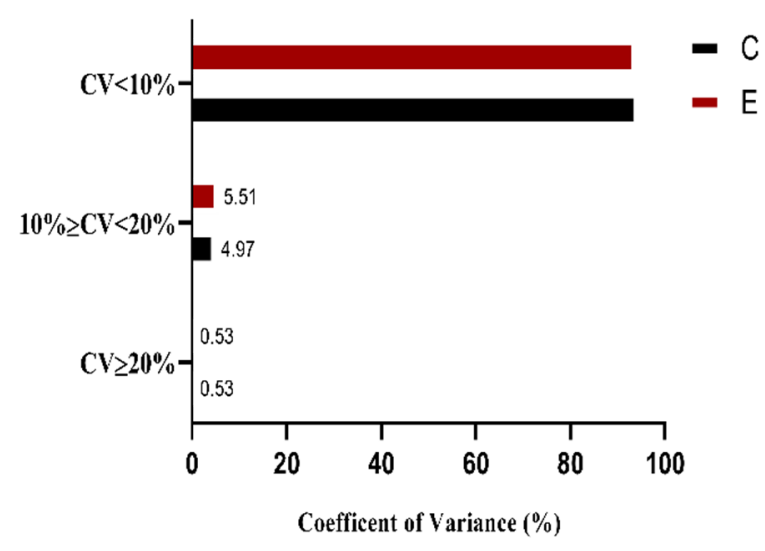

B

Figure 5. Precision of proteomic quantification. The stability of proteomics data was determined by estimating the Pearson's correlation coefficient between the replicates of each group $\left(\mathrm{C}=20 \% \mathrm{O}_{2}\right.$ and $\mathrm{E}$ $=5 \% \mathrm{O}_{2}$ ). A significant correlation was found between the replicates of both groups (A). The reliability of the data was further supported by variance analysis, as more than $90 \%$ of the proteins from both groups had a coefficient of variance of less than $10 \%(\mathbf{B})$. For each replicate $(n=3), 6$ hatched blastocysts from each group $(n=2)$ were included in proteomic analysis. 

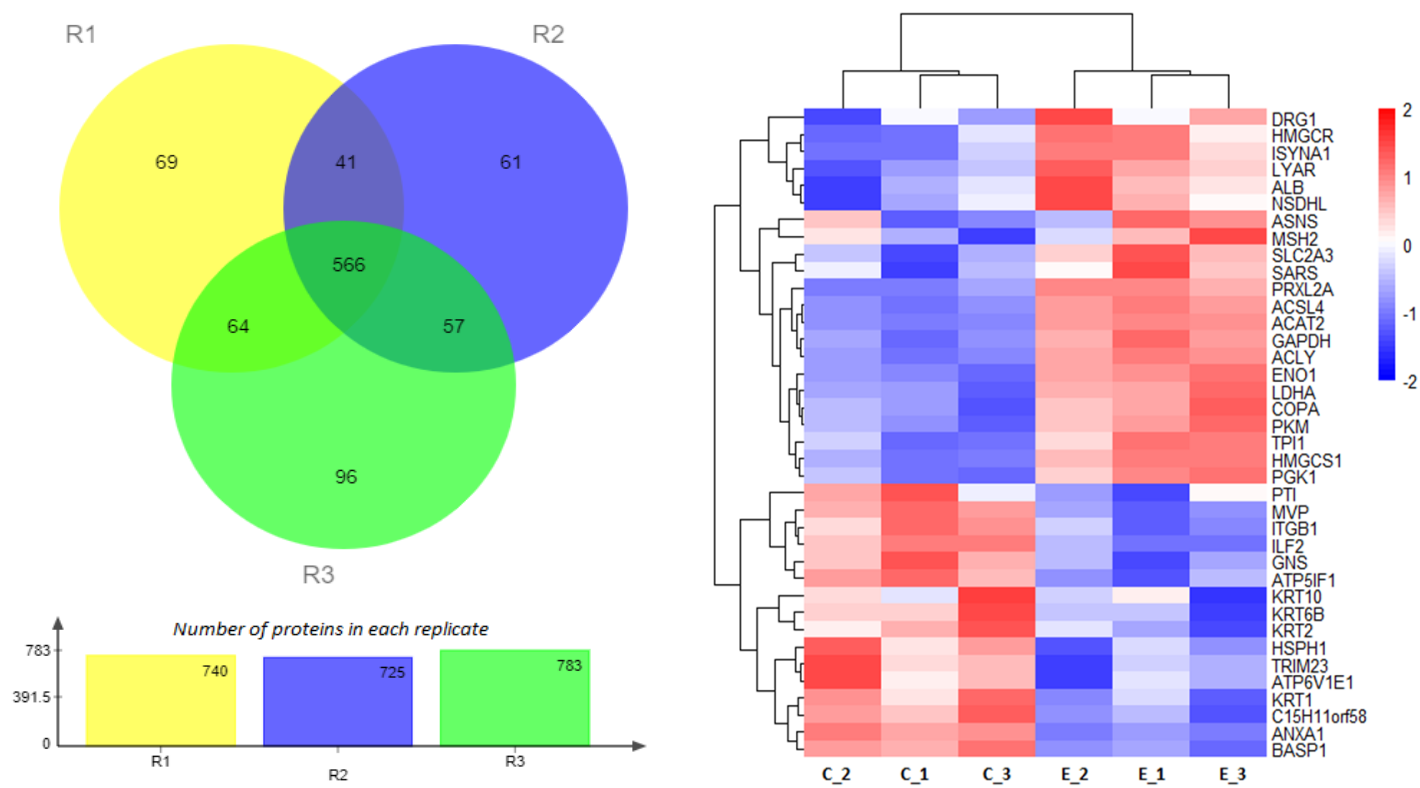

A

B

Figure 6. Protein profile obtained by labelled iTRAQ LC-MS/MS Analysis. Venn diagram showing the overlap of the quantified proteins within the three replicates (R1, R2 and R3). About $72.28 \%$ (566) of all the proteins (954) were found in every replicate, showing the good conformance of the samples (A). Heatmap presenting the distribution of differentially expressed proteins $\left(\log _{2} \mathrm{FC}\left[\frac{5 \%}{20 \%}\right]>20 \%, p<0.05\right)$. Pink and blue bars showing proteins that are significantly upregulated (25) and downregulated (18) in the $5 \%$ oxygen group in comparison with $20 \%$ oxygen group (B). The uncharacterized differentially expressed proteins have been omitted from the heatmap. C and E correspond to $20 \%$ and $5 \%$ oxygen, respectively.

\subsubsection{Gene Ontology Analysis of Differentially Expressed Proteins}

The differentially expressed proteins were further classified by gene ontology annotation based on three categories: biological process, cellular component, and molecular function. The GO analysis was derived from the online database (http://bioinformatics.sdstate.edu/go/, ShinyGO v0.60, 18-09.2019). After biological processes GO analysis of proteins upregulated in 5\% O2 embryos, we found that the biological processes include metabolic process, cellular component organization and biological regulation (Figure 7A). The molecular function of these proteins was important in structural molecule activity, catalytic activity and antioxidant activity. The results of the cellular component demonstrated that these proteins were mainly associated with membrane, organelle and protein-containing complexes. The GO analysis of downregulated proteins was conducted and analyzed the biological process (Figure 7B). We found that it includes cellular process, metabolic process and developmental process proteins. The molecular functions mainly include binding and catalytic activity. The results of the cellular component include cell part, organelle part and protein-containing complex. 


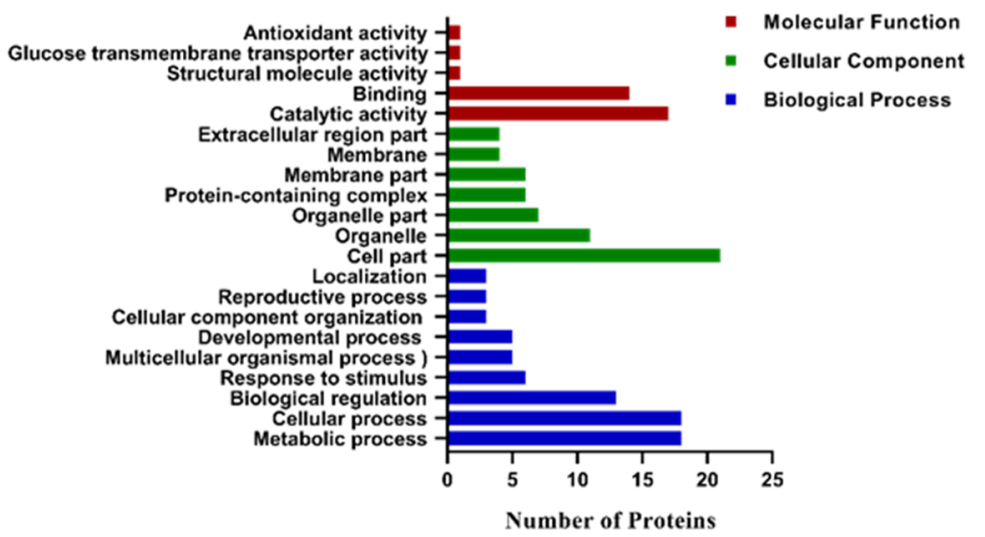

A

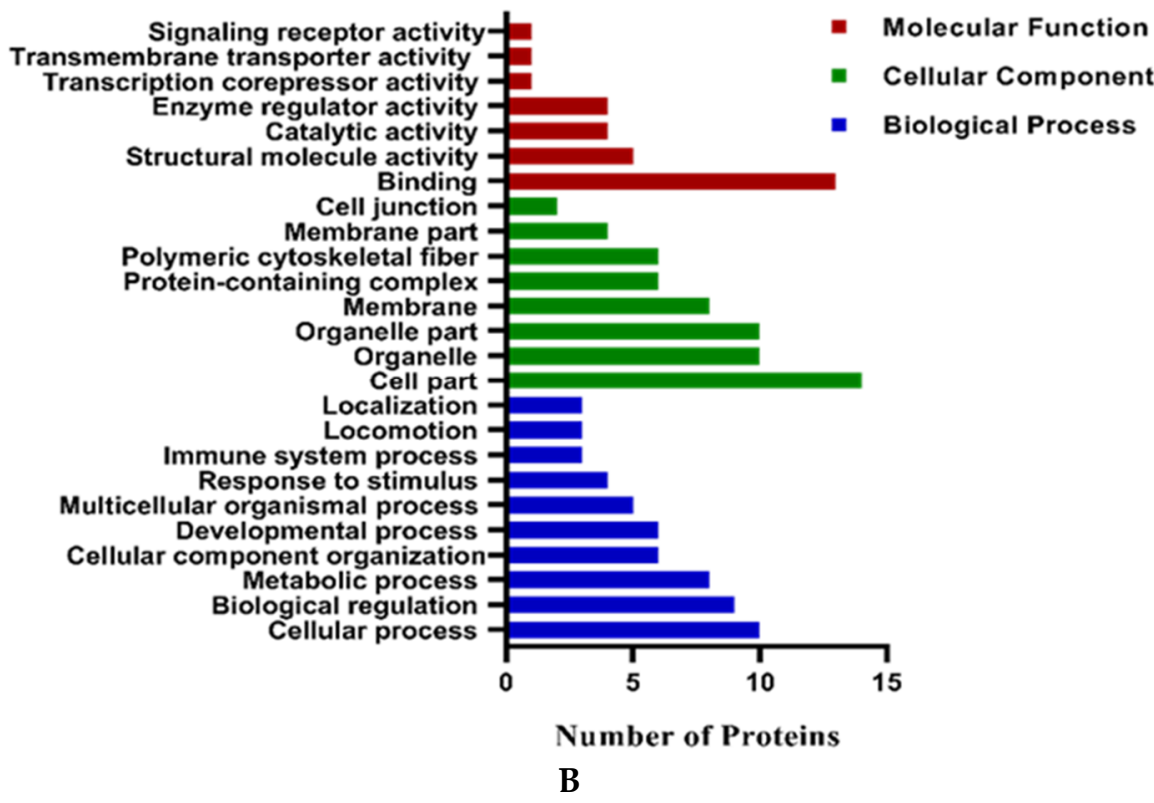

Figure 7. Gene ontology analysis of upregulated (A) and downregulated (B) proteins in $5 \% \mathrm{O} 2$ embryos. Proteins were classified according to cellular localization, biological processes and molecular functions. The results are displayed as a number of proteins classified to each category.

\subsubsection{KEGG Analysis of Differentially Expressed Proteins}

The identified differentially expressed proteins were analyzed based on the Kyoto Encyclopedia of Genes and Genomes (KEGG) database. Our results identify that upregulated proteins in 5\% O2 embryos were mainly enriched in glycolysis, pyruvate metabolism, fatty acid degradation, terpenoid backbone synthesis and inositol phosphate metabolism (Figure 8). The downregulated proteins in 5\% $\mathrm{O} 2$ embryos were mainly enriched in phagosome activity (Figure 8). 


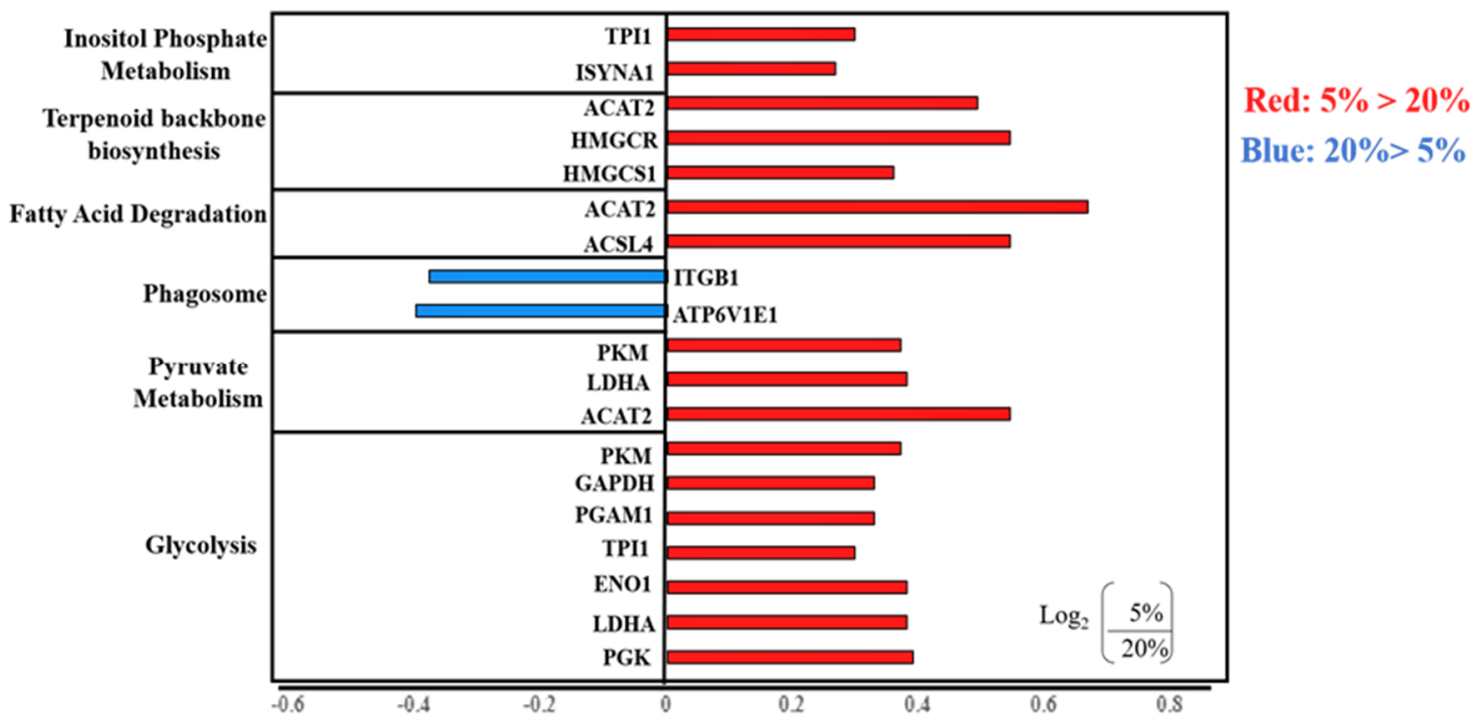

Figure 8. KEGG pathway analysis of differentially expressed proteins, Red colour shows upregulation and blue colour shows downregulation of protein levels in 5\% oxygen group.

\subsubsection{Proteome Profile Validation by Real Time Quantitative PCR}

The proteomics data were validated by real time quantitative PCR. The four genes regulating aerobic glycolysis were selected for the validation of the results. The gene involved in glucose transport (GLUT3, also known as SLC3A2), a key regulator of glycolysis, phosphofruktokinsae-1 (PFK1), glycolysis intermediate, glyceraldehyde phosphate dehydrogenase (GAPDH) and the gene responsible for the conversion of pyruvate to lactate (LDHA) were selected for RT-qPCR. The qPCR analysis revealed significant differences in mRNA expression level between $5 \%$ oxygen and $20 \%$ Oxygen among all four up-regulated proteins and thus validated the findings of proteomic analysis (Figure 9).

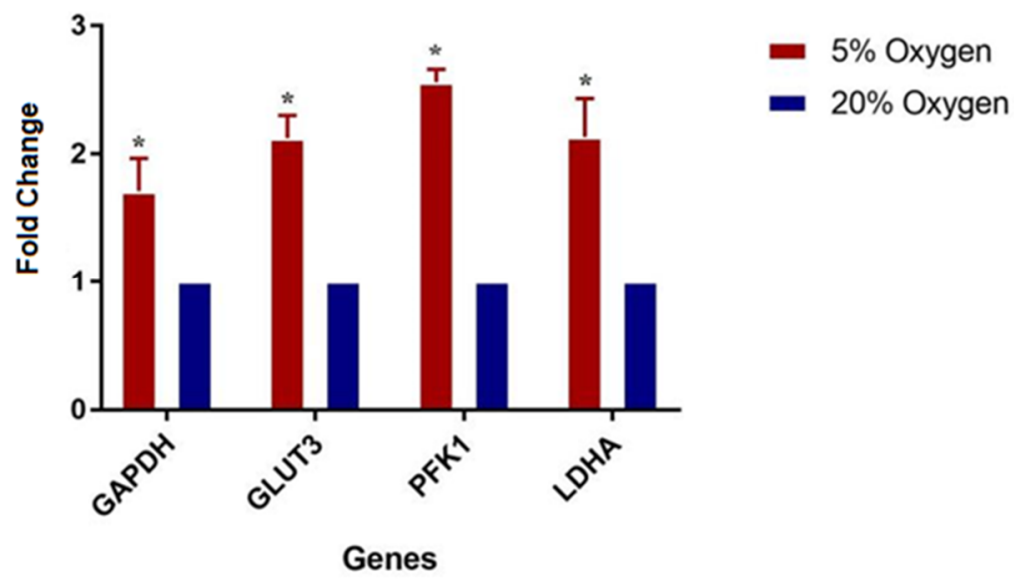

Figure 9. The real time qPCR analysis showing the elevated expression of GAPDH, GLUT3, PFK1 and LDHA in embryos cultured under low oxygen as compared to atmospheric oxygen. Asterisk $\left(^{*}\right)$ indicates the significant difference $(p<0.05)$ between the groups.

\subsubsection{Fluorescent intensity of Lipids}

The intensity of lipid droplets was measured using Nile red staining. The analysis showed that fluorescent intensity was higher $(p<0.05)$ in blastocysts cultured under atmospheric oxygen (Figure 10A). The representative micrographs of hatched blastocysts cultured under atmospheric and physiological oxygen are shown in Figure 10B,C, respectively. 


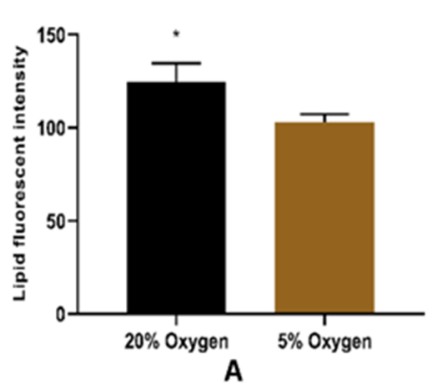

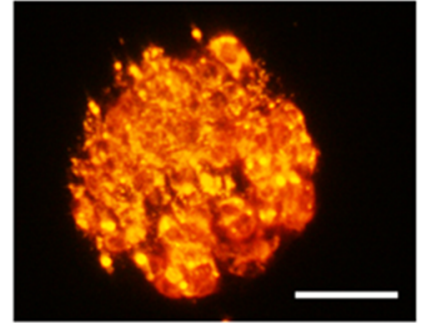

B

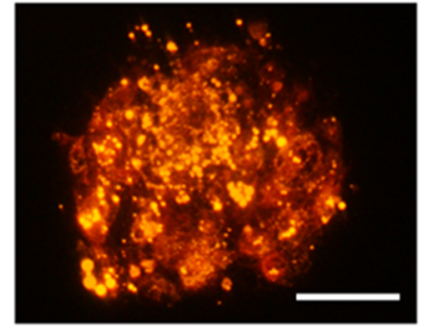

C

Figure 10. Fluorescent analysis of Lipid. Embryos cultured under atmospheric oxygen showed higher fluorescent intensity (A). Photomicrographs of Nile Red stained blastocysts: (B) 20\% Oxygen and (C) 5\% Oxygen. The images (Figure 10B,C) were captured with microscope (50i; Nikon, Japan) at 200× resolution. Asterisk $(*)$ indicates the significant difference $(p<0.05)$ between the groups.

\section{Discussion}

Oxygen regulation is crucial to embryonic development. During the preimplantation development in vivo, the embryo experiences a low-oxygen microenvironment, typically ranging from $2 \%$ to $8 \%[10,42-45]$. This oxygen tension contrasts with that present in the atmosphere (20\%). Simultaneously, perusal of the literature has suggested a growing consensus on the beneficial effects of lower oxygen on in vitro embryo development [46-48]. However, a few studies have shown no improvement in embryo developmental potential under reduced oxygen tension [14,15], signifying the importance of evaluating the influence of oxygen on embryos of individual species. Furthermore, the molecular mechanism of oxygen mediating embryo development is not yet clear. Therefore, we have evaluated the embryo development under reduced and atmospheric oxygen levels and determined the molecular mechanism of embryo development under different oxygen levels by using LC-MS/MS based proteomics approach.

\subsection{Physiological Oxygen Improves Morphological Parameters of Embryo Development}

During the embryo development in vivo, the requirement of oxygen varies according to the stage of embryonic development [49]. Such precise control of oxygen level is not possible or difficult to maintain in vitro. Due to this reason, it would be more feasible to find a specific oxygen level at which maximum embryo development may be obtained. It is well established that an elevated oxygen level leads to reactive oxygen species production, which in turn generates oxidative stress and, consequently, cell death occurs $[50,51]$. The present study has shown that physiological oxygen does not affect the cleavage of embryos. However, it increases the proportion of embryos developing to the blastocyst and hatched blastocyst stage. There are studies that have shown improved embryo development under low oxygen [12]. However, a few studies have suggested that a higher $\mathrm{O}_{2}$ level is more suitable for embryo production in bovines [52]. There are also studies which have reported that varying oxygen level does not affect the in vitro embryo development $[15,53]$. The variable results could be attributed to the use of different types of culture medium. We have shown that embryos had greater developmental kinetics under $5 \% \mathrm{O}_{2}$ and they have higher cell count, suggesting that physiological $\mathrm{O}_{2}$ is more suitable for buffalo embryo production. Moreover, blastocyst produced under low oxygen had a higher cryo-survival ability, as demonstrated by higher hatching rate post-warming.

\subsection{Embryos Developed under Low Oxygen Showed Pronounced Warburg Effect}

The present study has shown that embryos under low oxygen exhibit, in terms of proteomic profile, the metabolic adaptation, recognized as the Warburg Effect (Figure 11). The characteristic feature of the Warburg Effect is the increased glucose uptake and fermentation of glucose to lactate, supports rapid cell growth [54]. The glucose uptake by the cell is facilitated by GLUT3 protein, also known as Solute Carrier Family 2 Member 3 (SLC2A3), which is a potential high-affinity glucose carrier. During embryo development, GLUT3 is specific to the morula and blastocyst stages [55]. The increased 
expression of GLUT3 suggests a higher uptake of glucose by embryos incubated in a low oxygen environment, which is a signature of more viable embryos [56,57].

One of the hallmarks of the Warburg Effect is that pyruvate is directed away from the tri-carboxylic acid cycle and metabolized to lactate, resulting in a buildup of glycolytic intermediates [58]. The present study demonstrated the accumulation of enzymes involved in six chemical reactions of glycolysis (Figure 9) in embryos cultured under $5 \% \mathrm{O}_{2}$. Although ATP production from Warburg Effect is less efficient as compared to oxidative phosphorylation, it efficiently meets the demand for the generation of macromolecules, such as nucleic acid, in order to facilitate cell proliferation [58-60]. The elevated levels of glycolysis intermediates are proposed to increase R5P (Ribose 5-phosphate) and NADPH production, which are required for nucleic acid production and maintaining cellular redox status.

Pyruvate, the end product of glycolysis, may enter the TCA cycle or convert to lactate. The conversion of the pyruvate to lactate is catalyzed by LDHA, which is supposed to maintain the $\mathrm{NAD}^{+}$level that supports elevated glycolysis [61]. The embryos under low oxygen showed increased expression of LDHA, which is the key feature of the Warburg Effect. The real time quantitative PCR validated the findings of the proteomics data, as the protein involved in glucose uptake (GLUT3), glycolysis intermediates (PFK1, GAPDH) and protein involved in lactate production (LDHA) showed upregulation under $5 \% \mathrm{O}_{2}$. Taken together, embryos cultured under physiological oxygen levels showed pronounced features of the Warburg Effect, which may be associated with increased developmental competence of embryos under low oxygen.

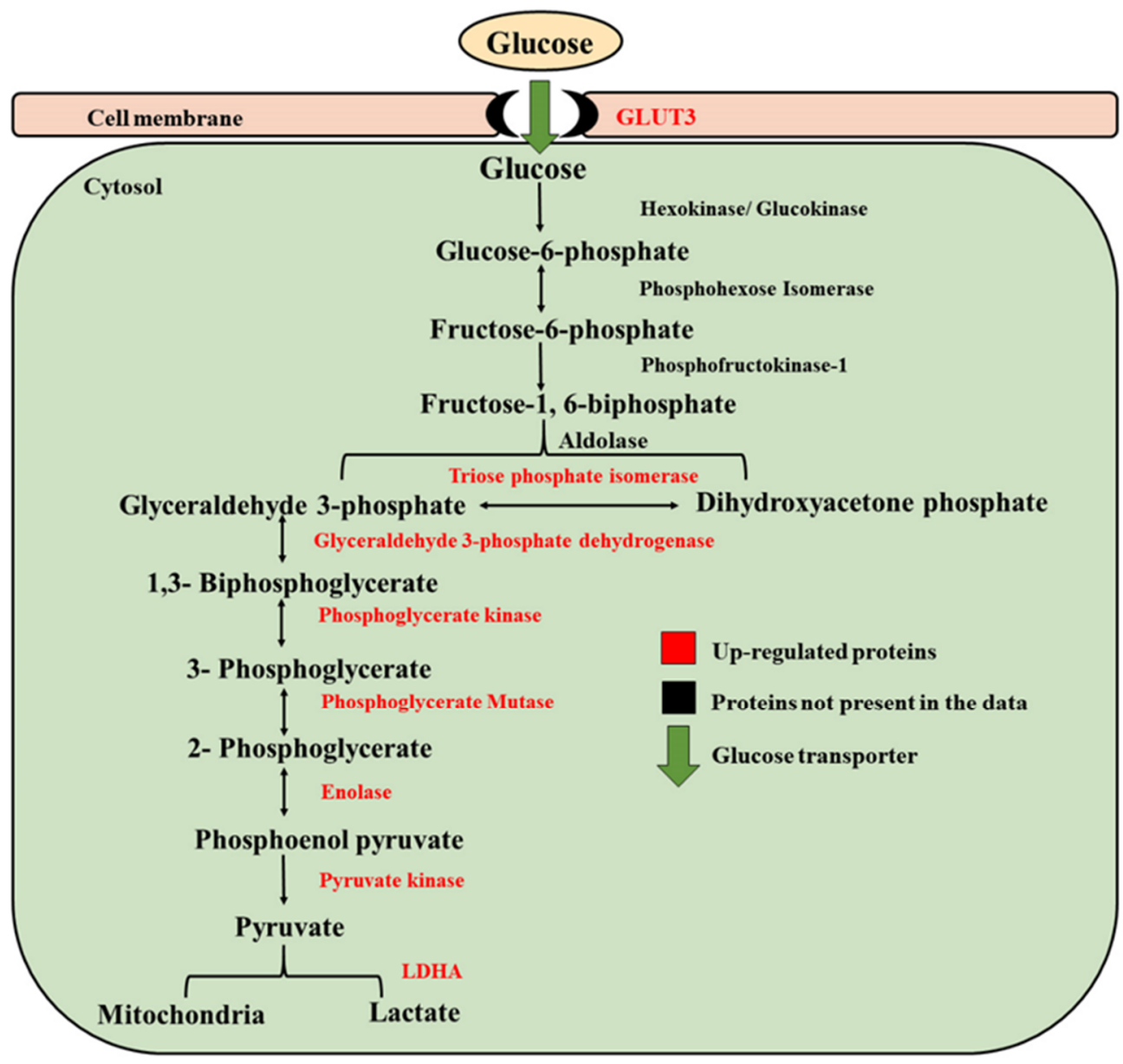

Figure 11. Regulation of enzymes involved in aerobic glycolysis (Warburg Effect). Red colour shows the upregulation of protein levels in 5\% oxygen. Green arrow shows the transport of glucose molecule from outside of the cell to inside through cell membrane, facilitated by glucose transporter (GLUT3). 


\subsection{Modification in the Lipid Composition might be Associated with Increased Cryo-Survival Ability of Embryos Cultured under Low Oxygen}

Buffalo embryos have higher lipid content, which hampers the success of cryopreservation [62]. The present study has shown that buffalo embryos cultured under physiological oxygen had a higher cryo-survival ability. The proteomic analysis demonstrated the upregulation of proteins involved in the degradation of lipids and cholesterol biosynthesis in embryos cultured under physiological oxygen. Simultaneously, the fluorescent intensity of lipids, an indicator of the density of lipid droplets [63], was low in embryos cultured under low oxygen. Here, we suggested that the better cryo-survival ability of the embryos under $5 \% \mathrm{O} 2$ may be related to the changes in lipid metabolism, ending in a lower content of lipid droplets.

Generally, the utilization of the IVEP is important for genetic improvement and selection [64]. Embryos generated through IVEP should be immediately transferred to recipients or cryopreserved. Management of recipient herds for immediate transfers is costly and time consuming. Therefore, embryo cryopreservation is the preferred method, as fewer management procedures are required by using this technique. However, cryo-survival rate of in vitro produced embryos is significantly lower as compared to in vivo embryos [65]. Eventually, the conception rate of cryopreserved in vitro embryos is considered too low for commercial use.

Attempts to improve embryo cryopreservation are based mainly into two major approaches: modification of the cryopreservation technique or cells themselves. All mammalian cell membranes consist of the lipid bilayer that mainly contains phospholipids. Each phospholipid has two fatty acid tails that can differ in length and saturation level. The properties of fatty acid tails are essential for strengthening the membrane for cryopreservation. Cryopreservation can damage membrane integrity, thereby causing membrane chilling injuries [66,67]. Cryoresistance of the cells may be improved through making their membranes more fluidic [68]. Membrane fluidity is influenced by the level of unsaturation in phospholipids and the amount of cholesterol present in the membrane.

In the present study, the proteomic analysis showed elevated expression of proteins involved in cholesterol synthesis (HMGCS1 and HMGCR) in embryos cultured under low oxygen (Figure 9). 3-hydroxy-3-methylglutaryl-coa synthase 1 (HMGCS1) is an enzyme that condenses acetyl-CoA with acetoacetyl-CoA to form HMG-CoA, which is the substrate for HMG-CoA reductase (HMGCR). HMGCR is a rate limiting enzyme in the cholesterol biosynthetic pathway [69]. The increased expression of HMGCS1 and HMGCR suggests that embryos cultured under low oxygen may have a higher cholesterol level that could be the reason for their better cryo-survival ability. Increasing the cholesterol level of the membrane of bovine cells has been characterized to improve cryotolerance [68]. The KEGG analysis of differentially expressed proteins from the present study suggested that low oxygen embryos had increased expression of fatty acid degradation proteins (ACAT2 and ACSL4). These findings are supported by the low lipid fluorescent intensity in embryos under physiological oxygen. The fluorescent intensity is an indicator of density of lipid droplets [63]. The higher lipid level is attributed to the poor cryo-survival ability of embryos [62]. The proteomic and fluorescent intensity analysis implies that the better cryo-survival ability of embryos under low oxygen may be due to lower lipid levels. Acetyl-coenzyme A acetyltransferase 2 (ACAT2) is an enzyme which catalyzes the reaction and converts two acetyl Co-A into acetoacetyl Co-A [70]. Acyl-CoA synthetase long chain family member 4 (ACSL4) is an enzyme that utilizes free long chain fatty acids and converts them into fatty acyl-CoA esters, and thereby play a key role in lipid biosynthesis and fatty acid degradation. This enzyme preferentially utilizes arachidonic acid as a substrate [71]. As arachidonic acid is a polyunsaturated fatty acid, we propose that increased expression of ACSL4 protein may have enhanced the level of unsaturation in the phospholipid bilayer of the membrane, thereby improving the cryo-survival ability of embryos cultured under low oxygen. However, we recommend that these hypotheses should be confirmed by using lipidomics approach. 


\section{Materials and Methods}

All the chemicals and reagents were obtained from Sigma-Aldrich (St. Louis, MO, USA), unless otherwise noted. No animals were used for this work. All studies were conducted on slaughterhouse-derived materials. The schematic representation of the experimental design is briefly described in Figure 12.

A

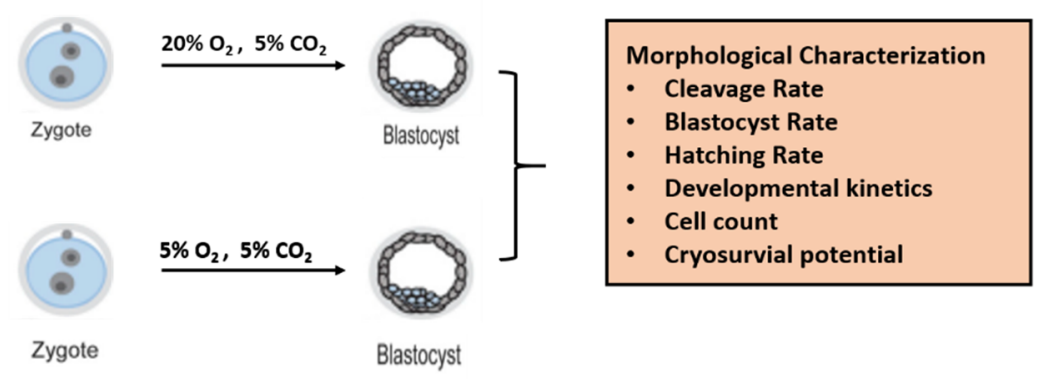

\section{B}

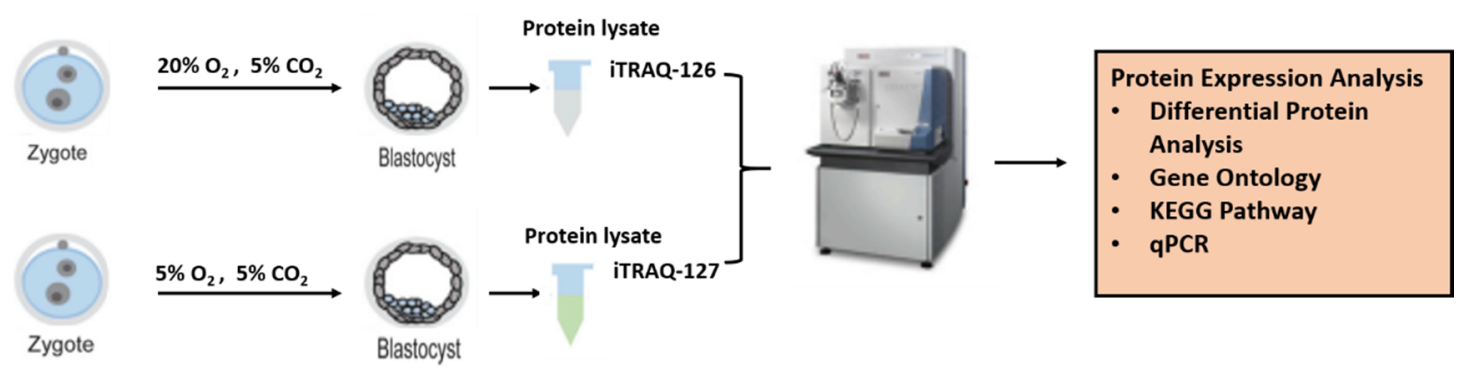

Figure 12. Schematic illustration of experimental design. Buffalo embryos were cultured in $5 \%$ or $20 \%$ oxygen and evaluated for morphological parameters of embryo development (A). Alterations in embryo proteome after culturing in different oxygen levels ( $5 \%$ vs $20 \%$ ) were assessed by using labelling based iTRAQ quantitative proteomics approach (B).

\subsection{Morphological Parameters of Embryo Development under Different Oxygen Tension (5\% vs. 20\%)}

\subsubsection{In Vitro Oocyte Maturation, Fertilization and Culture}

Buffalo ovaries were collected from a local abattoir in Nanning, China, and immediately (within $2 \mathrm{~h}$ ) transported to the laboratory. Cumulus oocyte complexes (COCs) were aspirated from follicles (2-8 $\mathrm{mm}$ ) using $18 \mathrm{G}$ needles connected to $10-\mathrm{mL}$ disposable syringes containing 2-mL collection medium (Hepes-buffered TCM-199 supplemented with 3\% newborn serum) and subsequently washed 3 times in the same medium. Good quality COCs (oocyte with intact and compact cumulus cells) were selected and matured at $38.5{ }^{\circ} \mathrm{C}$ under $5 \% \mathrm{CO}_{2}$ air atmosphere for $22-24 \mathrm{~h}$ in maturation medium (TCM-199 supplemented with $10 \%$ fetal bovine serum, $100 \mathrm{mM}$ cysteamine, $0.5 \mu \mathrm{g} / \mathrm{mL} \mathrm{FSH}, 1 \mu \mathrm{g} / \mathrm{mL}$ $\mathrm{E}_{2}$ and $5 \mu \mathrm{g} / \mathrm{mL} \mathrm{LH}$ ). Fertilization was then performed in $20 \mu \mathrm{L}$ of fertilization media (Tyrode's medium with $0.6 \%$ BSA, $2.5 \mathrm{mM}$ caffeine sodium benzoate, and $20 \mathrm{mg} / \mathrm{mL}$ heparin) for $6-8 \mathrm{~h}$ in $5 \% \mathrm{CO}_{2}$ at $38.5^{\circ} \mathrm{C}$. At the end of insemination, cumulus cells and sperms were separated by gentle pipetting and presumptive zygotes were washed twice in Hepes-buffered TCM 199 medium (supplemented with $3 \%$ newborn bovine serum) and three times in embryo culture medium, BO-IVC (Falmouth, UK). The presumptive zygotes were randomly divided into two groups and cultured in a standard incubator $\left(5 \% \mathrm{CO}_{2}\right.$ and $20 \% \mathrm{O}_{2}$ ) or in a low-oxygen chamber $\left(5 \% \mathrm{CO}_{2}\right.$ and $\left.5 \% \mathrm{O} 2\right)$ at $38.5^{\circ} \mathrm{C}$ for eight days. The experiment was conducted in 3 replicates, and a total of 576 and 567 embryos were cultured in the $20 \%$ and $5 \% \mathrm{O}_{2}$ groups, respectively. The blastocyst and hatching rate were assessed at day 7 , and development rates were recorded at days $5,6,7$ and 8 post-inseminations. 


\subsubsection{Cell Staining}

Cell staining was performed on hatched blastocysts from both ( $n=15$ each) the groups on day 7. After washing three times in Dulbecco's Phosphate Buffer Saline (DPBS), embryos were stained with Hoechst $(33342,1 \mathrm{mg} / \mathrm{mL}$ ) for $25 \mathrm{~min}$ in the dark at room temperature. The slides were sealed with glycerin and cells were counted under an epifluorescence microscope under $\times 200$ and $\times 400$ magnifications (Figure 3 in the results section).

\subsubsection{Embryo Quality Scoring}

The embryo quality scoring system was established for the buffalo embryos according to the definitions presented in the manual of the European Society of Human Reproduction and Embryology. Briefly, blastocysts stage embryos were specified with different scores (1-6) based on the degree of expansion. The blastocysts with less than $50 \%$ blastocoel cavity were allotted score 1 (Figure 13A); score 2 blastocysts had half or more than half blastocoel cavity (Figure 13B); score 3 blastocysts were those in which the blastocoel completely filled the embryo (Figure 13C); blastocoel was greater than the original volume of the embryo in score 4 blastocysts (Figure 13D); score 5 blastocysts or hatching blastocysts (Figure 13E) in which trophoblast cells were herniating through natural breach of zona pellucida (ZP); and score 6 blastocysts or hatched blastocysts were those in which the blastocysts had completely escaped through a natural breach in ZP (Figure 13F).

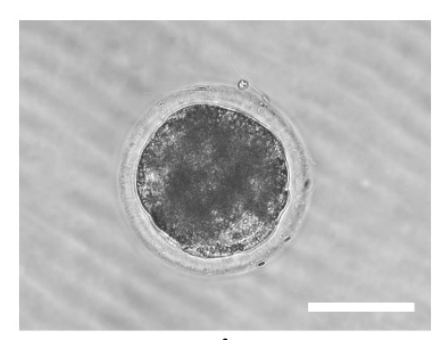

A

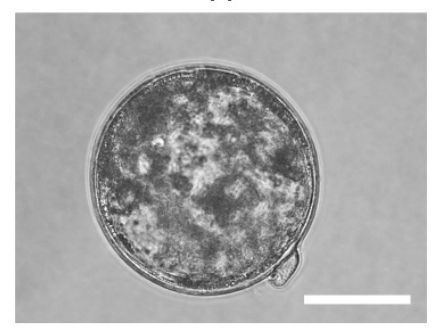

C

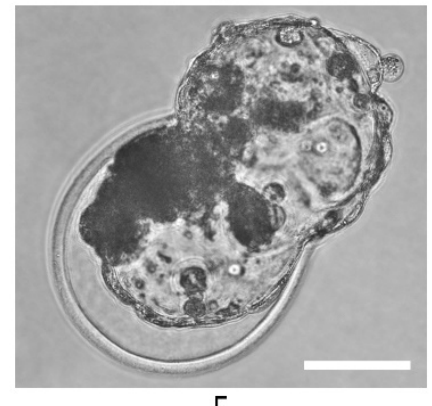

$\mathrm{E}$

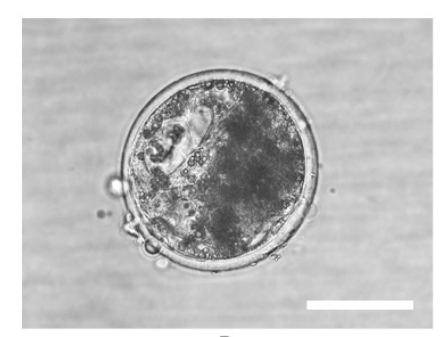

B

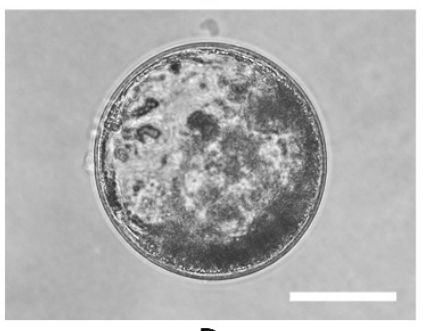

D

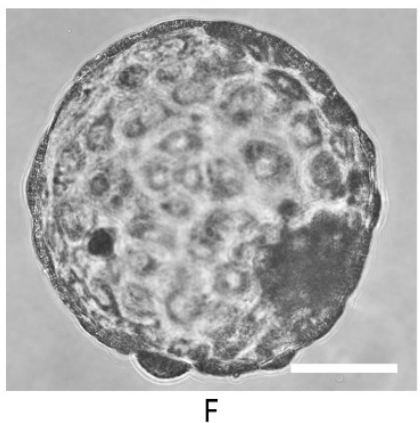

$\mathrm{F}$

Figure 13. Embryo quality scoring based on expansion. Embryos were allotted scores of 1 (A), 2 (B), 3 (C), 4 (D), 5 (E) and 6 (F). The images were captured with microscope (50i; Nikon, Japan) at 200x resolution. 


\subsubsection{Vitrification, Thawing and Hatching Rate of Blastocysts}

All equilibration, vitrification and thawing solutions were prepared in $25 \mathrm{mM}$ HEPES-buffered TCM199 supplemented with 10\% FBS. Solutions were brought to room temperature before use. Vitrification was performed according to the method reported by Yang et al. [31]. Briefly, one end of a $0.25-\mathrm{mL}$ straw was cut out with a sharp scalpel to form an open pole. Blastocysts (non-hatched) were equilibrated in equilibration solution for $5 \mathrm{~min}$, then transferred into a vitrification solution A ( $10 \%$ ethylene glycol $+10 \%$ DMSO) for $30 \mathrm{sec}$ and another $30 \mathrm{sec}$ in vitrification solution B $(20 \%$ ethylene glycol $+20 \%$ DMSO $+0.5 \mathrm{M}$ sucrose) and immediately placed on the tip of the open pole, and rapidly plunged into liquid nitrogen. Straws were stored in liquid nitrogen for at least $24 \mathrm{~h}$ before thawing. Thawing was performed in thawing solution ( $0.5 \mathrm{M}$ sucrose) for $5 \mathrm{~min}$, and then embryos were placed in equilibration medium for $5 \mathrm{~min}$. Subsequently, blastocysts were cultured for $72 \mathrm{~h}$ and assessed for hatching rate.

\subsubsection{Statistical Analysis}

The data obtained for cleavage, blastocyst and hatching rate were statistically analyzed by using Fisher's exact test. The data obtained for embryo quality scoring were analyzed by using the chi-square test. The data for cell count were normalized by arcsine transformation and tested by Wilcoxon test. All the statistical analysis was performed using GraphPad Prism 7 software

\subsection{Proteomic Analysis of Embryos Cultured under 5\% or $20 \%$ Oxygen Tension}

\subsubsection{Cell Lysis}

The proteomic analysis was performed by extracting proteins from the hatched blastocysts $(n=6$ blastocyst per replicate) cultured under varying oxygen levels (5\% or $20 \%$ ) in 3 biological replicates. The cells were lysed in $20 \mu \mathrm{L}$ lysis buffer ( $5 \mathrm{mM}$ EDTA, $5 \mathrm{mM}$ Egtazic acid, $10 \mathrm{mM} \mathrm{NaOH}, 1 \times$ Protease Inhibitor Cocktail, $10 \mathrm{mM}$ HEPES (pH 8.5), $10 \mathrm{mM}$ dithiothreitol, 1\%SDS) and homogenized by ice-cooled sonification for $10 \mathrm{~min}$. Then, the precipitation of proteins was done by adding $4 \mu \mathrm{L}$ processed beads [72] and $20 \mu \mathrm{L}$ of TFE (trifluoroethanol) and performing the sonification of each tube in the ice bath for $15 \mathrm{~min}$. After this, $0.75 \mu \mathrm{L}$ of $0.1 \%$ formic acid was added to each tube, and then lysate was incubated at $95{ }^{\circ} \mathrm{C}$ for $5 \mathrm{~min}$ and placed on ice for $30 \mathrm{sec}$. Samples were incubated at $45^{\circ} \mathrm{C}$ for $30 \mathrm{~min}$ and then, $5 \mu \mathrm{L} 400 \mathrm{mM}$ iodoacetamide (IAA) were added to each tube and incubated at $24^{\circ} \mathrm{C}$ for $30 \mathrm{~min}$. To stop the reaction, $5 \mu \mathrm{L}$ of $200 \mathrm{mM}$ DTT (dithiothreitol) was added to each tube.

\subsubsection{Protein Purification}

For protein purification, $1 \%$ formic acid $(5 \mu \mathrm{L})$ was added to $10 \mu \mathrm{L}$ of the lysate (in order to acidify the solution) and then $15 \mu \mathrm{L}$ acetonitrile was added to the solution. The mixture was incubated at room temperature for $8 \mathrm{~min}$, and the tube was then placed at a magnetic stand for $2 \mathrm{~min}$ at room temperature. The supernatant was discarded, and the pellet was washed with $70 \%$ ethanol $(200 \mu \mathrm{L})$. The pellet was washed twice with $70 \%$ ethanol. Then, the supernatant was removed, and acetonitrile $(180 \mu \mathrm{L})$ was added into the pellet and shifted to the magnetic stand. The pellet solution was further incubated for $15 \mathrm{~min}$ dried at room temperature for $30 \mathrm{sec}$. The peptide digestion was performed by adding $5 \mathrm{uL}$ digestion solution (5:1 of $50 \mathrm{mM}$ HEPES and trypsin) and incubating at $37^{\circ} \mathrm{C}$ for $14 \mathrm{~h}$.

\subsubsection{Peptide Recovery and Preparation}

The $5 \mu \mathrm{L}$ of digested peptides and $195 \mu \mathrm{L}$ acetonitrile were mixed in a tube and incubated for $8 \mathrm{~min}$. The PCR tube was placed at the magnetic stand and incubated again at room temperature for $2 \mathrm{~min}$. The supernatant was discarded and $180 \mu \mathrm{L}$ acetonitrile was added to the magnetic stand and incubated for $15 \mathrm{sec}$. After the removal of the supernatant, $2 \%$ DMSO was added to reconstitute the magnetic bead and sonicated for $1 \mathrm{~min}$ to improve the recovery rate. The tube was centrifuged briefly 
(2 sec) and placed on the magnetic stand. The supernatant was separated in a new tube containing $1 \mu \mathrm{L}$ of $1 \%$ formic acid.

\subsection{4. iTRAQ Labelling}

For iTRAQ labelling, peptides were reconstituted in $12 \mu \mathrm{L}$ of $500 \mathrm{mM}$ triethylammonium bicarbonate (TEAB) by sonification for $5 \mathrm{~min}$. Then, isopropanol $(150 \mu \mathrm{L})$ was added to dissolve $0.8 \mathrm{mg}$ of iTRAQ tag and placed for $5 \mathrm{~min}$. After mixing, $15 \mu \mathrm{L}$ iTRAQ tag was added to each tube of peptide and incubated the tube at room temperature for $2 \mathrm{~h}$. Samples from $20 \%$ and $5 \%$ oxygen group were labelled as 126 and 127, respectively. The peptide mixtures were then pooled and dried by vacuum centrifugation.

\subsubsection{Mass Spectrometry}

The sample was reconstituted with $10 \mu \mathrm{L}$ of mobile phase A ( $99.9 \%$ water and $0.1 \%$ formic acid); sonicated in a water bath for $5 \mathrm{~min}$ and centrifuged at 12,000 $\mathrm{g}$ for $5 \mathrm{~min}$, and slowly added to the sample bottle with a pipette (to avoid air bubbles). The mobile phases used in the LC-MS elution: mobile phase A ( $98 \%$ water, $2 \%$ acetonitrile, and $0.1 \%$ formic acid); mobile phase B ( $98 \%$ acetonitrile, $2 \%$ water, and $0.1 \%$ formic acid). For iTRAQ-labeled samples, the loading amount was $3 \mu \mathrm{L}$, and the elution was performed at a rate of $300 \mathrm{~nL} / \mathrm{min}$. The maximum pressure (600 bar) was applied, and the gradient changes over $145 \mathrm{~min}$ were observed (buffer B is at $0 \%-15 \%$ for $5 \mathrm{~min} ; 100 \mathrm{~min}$ at $15 \%-27 \%$, $20 \mathrm{~min}$ at $27 \%-40 \%, 20 \mathrm{~min}$ at $40 \%-98 \%$ ). Data were acquired on qExactive MS (Thermo Scientific) using a data-dependent method. The first 12 peaks were selected after higher-energy collisional dissociation (HCD) fragmentation for tandem-MS/MS (MS2) analysis. Scans covered a mass range of 350-1800 with a resolution of 60,000, HCD fragmentation. The normalized collision energy was set at 33 .

\subsubsection{Database Search Settings}

The protein database for Bos Taurus (UP000009136, 24078 sequences, published March 2017) was downloaded from Uniport database. Then, data were imported to Proteome Discoverer software v1.3 and the database search parameters were set: we selected iTRAQ8plex (+304.205 Da) for the quantification method, trypsin full for the digestion method, and set precursor mass tolerance to $20 \mathrm{ppm}$; fragment mass tolerance was set to $0.02 \mathrm{Da}$; dynamic modification was oxidation (+15.995 Da M); fixed modification was carbamidomethyl (+57.021 Da C); target FDR (false discovery rate) was set to 0.01 , target FDR (Relaxed) was set to 0.05, and the verification method used q-Value.2.9. The proteome profile of each replicate $(n=3)$ is listed in Supplementary Table S1-S3.

\subsubsection{Bioinformatics Analysis}

The variations and closeness between the replicates of each group were assessed by calculating the coefficient of variance and correlation. The differentially expressed proteins (DEPs) between the two groups were identified by using a web based EdgeR package [73]. A $p$-value $<0.05$ and $\log _{2} \mathrm{FC}\left[\frac{5 \%}{20 \%}\right]>20 \%$ were considered to be significant. The $\log _{2} \mathrm{FC}$ value is based on $\mathrm{m}$ value [73]; if $\log 2 \mathrm{FC}$ is 0 , it shows no change, and if $\log 2 \mathrm{FC}$ is 0.2 , it means $20 \%$ change. The DEPs are listed in Supplementary Table S4. The cellular component, molecular functions and biological processes of DEPs were identified and subjected to GO functional classification and enrichment analysis. The DEPs were also subjected to KEGG enrichment analysis. For GO and KEGG analysis, an online website (http://bioinformatics.sdstate.edu/go/, ShinyGO v0.60, 18-09.2019) was used keeping the FDR at 0.05.

\subsubsection{Real Time qPCR Analysis}

Total RNA was extracted from hatched blastocysts by using the protocol as described previously [74]. Extracted RNA was then transcribed into cDNA by using the reverse transcription kit 
(GoScript ${ }^{\mathrm{TM}}$ Reverse Transcription Mix, Random Primer Protocol, Promega). The Sybr green-based real time qPCR was performed in a thermocycler for real-time PCR (CFX96 Touch; BIO-RAD, USA). The primer pairs used for qPCR are listed in Supplementary Table S5. The experiment was performed in three replicates, with 10-12 blastocysts in each replicate. For each group of embryos, the expression levels of the target genes were normalized to the expression level of the endogenous control, ribosomal protein S15 (RPS-15). The RPS-15 is considered as one of the most stable endogenous control for buffalo embryos [75]. The Ct values for RPS 15 were almost similar between both of the groups. We determined the relative level of expression of each mRNA using the $2^{-\Delta \Delta \mathrm{Ct}}$ (normalized expression ratio) method [76].

\subsubsection{Assessment of Lipid Accumulation}

The lipid content was assessed by Nile Red staining in hatched blastocysts ( $n=15$, each group). The Nile red stock solution was prepared by dissolving Nile Red dye (Cat\# R-72485) at $1 \mathrm{mg} / \mathrm{mL}$ in DMSO and stored in the dark. Obtained blastocysts were washed in $0.01 \%$ PBS-PVP for $1 \mathrm{~min}$. Blastocysts were fixed in $4 \%$ formaldehyde solution at $4{ }^{\circ} \mathrm{C}$ for $24 \mathrm{~h}$. After fixation blastocysts were washed in $0.01 \%$ PBS-PVP to remove the fixative and stained with Nile Red $(10 \mu \mathrm{g} / \mathrm{mL})$ for $3 \mathrm{~h}$ at room temperature in dark condition taking all necessary precautions. The extra stain was removed by washing with $1 \%$ PBS-PVP and stained blastocysts were observed under a fluorescence microscope using FITC filter to capture the images with a $40 \times$ objective. Image analysis and fluorescent intensity were measured using Image J software. The statistical analysis was done by Wilcoxon test by using GraphPad Prism 8 software.

\section{Conclusions}

This study provides an insight into the mechanism of embryo development under physiological and atmospheric oxygen. We conclude that reduced oxygen provides a more conducive environment for buffalo embryo culture and improves blastocyst yield, hatching rate, developmental kinetics, cell count, as well as cryo-survival ability. The proteomic analysis data showed that the more significant developmental potential of the embryos under low oxygen might be due to the pronounced Warburg Effect. Alongside this, the cryo-survival ability of the embryos cultured under low oxygen was better; this might be linked with an increase in the expression of cholesterol biosynthesis proteins, higher unsaturated to saturated fatty acids ratio and fatty acid degradation proteins. These data provide a rich resource for further studies on utilizing the Warburg effect and lipid metabolism for improvement in embryo development.

Supplementary Materials: Supplementary materials can be found at http://www.mdpi.com/1422-0067/21/6/1996/ s1.

Author Contributions: Y.L. conceived the experiments; Q.S. and M.W. performed the embryology work and wrote the paper; L.P., A.A.W. and H.X. performed the proteomics experiment; L.X., X.L. and C.S.P. analyzed the proteomic data. All authors have read and agreed to the published version of the manuscript.

Funding: This research was jointly supported by Research Project of State Key Laboratory for Conservation and Utilization of Subtropical Agro-bioresources (SKLQ201504), Guangxi Natural Science Foundation (2018GXNSFAA138142) and Research Project of Guangxi Key Laboratory of Buffalo Genetics and Breeding (SNKF-2014-03).

Acknowledgments: The authors acknowledge the contributions of Dr. Sehrish Akbar for improving the English of the manuscript and Dr. Qiang Fu for assistance in mass spectrometry.

Conflicts of Interest: The authors declare no conflict of interest.

\section{References}

1. Food and Agriculture Organization of the United Nations (FAO). MILK and Dairy Products in Human Nutrition; Food and Agriculture Organization of the United Nations (FAO): Rome, Italy, 2013. 
2. Kussano, N.R.; Leme, L.O.; Guimaraes, A.L.; Franco, M.M.; Dode, M.A. Molecular markers for oocyte competence in bovine cumulus cells. Theriogenology 2016, 85, 1167-1176. [CrossRef] [PubMed]

3. Besenfelder, U.; Havlicek, V.; Kuzmany, A.; Brem, G. Endoscopic approaches to manage In Vitro and in vivo embryo development: Use of the bovine oviduct. Theriogenology 2010, 73, 768-776. [CrossRef] [PubMed]

4. Xu, J.; Chaubal, S.A.; Du, F. Optimizing IVF with sexed sperm in cattle. Theriogenology 2009, 71, 39-47. [CrossRef] [PubMed]

5. Gasparrini, B.; Boccia, L.; Marchandise, J.; Di Palo, R.; George, F.; Donnay, I.; Zicarelli, L. Enrichment of in vitro maturation medium for buffalo (Bubalus bubalis) oocytes with thiol compounds: Effects of cystine on glutathione synthesis and embryo development. Theriogenology 2006, 65, 275-287. [CrossRef]

6. Wale, P.L.; Gardner, D.K. The effects of chemical and physical factors on mammalian embryo culture and their importance for the practice of assisted human reproduction. Hum. Reprod. Update 2016, 22, 2-22. [CrossRef]

7. Ajduk, A.; Zernicka-Goetz, M. Quality control of embryo development. Mol. Asp. Med. 2013, 34, 903-918. [CrossRef]

8. Grupen, C.G. The evolution of porcine embryo In Vitro production. Theriogenology 2014, 81, 24-37. [CrossRef]

9. Jones, H.W., Jr.; Oehninger, S.; Bocca, S.; Stadtmauer, L.; Mayer, J. Reproductive efficiency of human oocytes fertilized In Vitro. Facts Views Vis. ObGyn 2010, 2, 169-171.

10. Fischer, B.; Bavister, B.D. Oxygen tension in the oviduct and uterus of rhesus monkeys, hamsters and rabbits. J. Reprod. Fertil. 1993, 99, 673-679. [CrossRef]

11. Guerin, P.; El Mouatassim, S.; Menezo, Y. Oxidative stress and protection against reactive oxygen species in the pre-implantation embryo and its surroundings. Hum. Reprod. Update 2001, 7, 175-189. [CrossRef]

12. Harvey, A.J. The role of oxygen in ruminant preimplantation embryo development and metabolism. Anim. Reprod. Sci. 2007, 98, 113-128. [CrossRef] [PubMed]

13. Elamaran, G.; Singh, K.P.; Singh, M.K.; Singla, S.K.; Chauhan, M.S.; Manik, R.S.; Palta, P. Oxygen concentration and cysteamine supplementation during In Vitro production of buffalo (Bubalus bubalis) embryos affect mRNA expression of BCL-2, BCL-XL, MCL-1, BAX and BID. Reprod. Domest. Anim. 2012, 47, 1027-1036. [CrossRef] [PubMed]

14. Betterbed, B.; Wright, R.W., Jr. Development of one-cell ovine embryos in two culture media under two gas atmospheres. Theriogenology 1985, 23, 547-553. [CrossRef]

15. Khurana, N.K.; Niemann, H. Effects of oocyte quality, oxygen tension, embryo density, cumulus cells and energy substrates on cleavage and morula/blastocyst formation of bovine embryos. Theriogenology 2000, 54, 741-756. [CrossRef]

16. Yang, Y.; Xu, Y.; Ding, C.; Khoudja, R.Y.; Lin, M.; Awonuga, A.O.; Dai, J.; Puscheck, E.E.; Rappolee, D.A.; Zhou, C. Comparison of 2, 5, and $20 \% \mathrm{O}_{2}$ on the development of post-thaw human embryos. J. Assist. Reprod. Genet. 2016, 33, 919-927. [CrossRef] [PubMed]

17. Karja, N.W.; Wongsrikeao, P.; Murakami, M.; Agung, B.; Fahrudin, M.; Nagai, T.; Otoi, T. Effects of oxygen tension on the development and quality of porcine in vitro fertilized embryos. Theriogenology 2004, 62, 1585-1595. [CrossRef]

18. Bernardi, M.L.; Flechon, J.E.; Delouis, C. Influence of culture system and oxygen tension on the development of ovine zygotes matured and fertilized In Vitro. J. Reprod. Fertil. 1996, 106, 161-167. [CrossRef]

19. Dahl, J.A.; Jung, I.; Aanes, H.; Greggains, G.D.; Manaf, A.; Lerdrup, M.; Li, G.; Kuan, S.; Li, B.; Lee, A.Y. Broad histone H3K4me3 domains in mouse oocytes modulate maternal-to-zygotic transition. Nature 2016, 537, 548. [CrossRef]

20. Flyamer, I.M.; Gassler, J.; Imakaev, M.; Brandão, H.B.; Ulianov, S.V.; Abdennur, N.; Razin, S.V.; Mirny, L.A.; Tachibana-Konwalski, K. Single-nucleus $\mathrm{Hi}-\mathrm{C}$ reveals unique chromatin reorganization at oocyte-to-zygote transition. Nature 2017, 544, 110. [CrossRef]

21. Guo, H.; Zhu, P.; Wu, X.; Li, X.; Wen, L.; Tang, F. Single-Cell methylome landscapes of mouse embryonic stem cells and early embryos analyzed using reduced representation bisulfite sequencing. Genome Res. 2013, 23, 2126-2135. [CrossRef]

22. Lu, F.; Liu, Y.; Inoue, A.; Suzuki, T.; Zhao, K.; Zhang, Y. Establishing chromatin regulatory landscape during mouse preimplantation development. Cell 2016, 165, 1375-1388. [CrossRef] [PubMed]

23. Wu, J.; Huang, B.; Chen, H.; Yin, Q.; Liu, Y.; Xiang, Y.; Zhang, B.; Liu, B.; Wang, Q.; Xia, W. The landscape of accessible chromatin in mammalian preimplantation embryos. Nature 2016, 534, 652. [CrossRef] [PubMed] 
24. Xue, Z.; Huang, K.; Cai, C.; Cai, L.; Jiang, C.-Y.; Feng, Y.; Liu, Z.; Zeng, Q.; Cheng, L.; Sun, Y.E. Genetic programs in human and mouse early embryos revealed by single-cell RNA sequencing. Nature 2013, 500, 593. [CrossRef] [PubMed]

25. Zhang, B.; Zheng, H.; Huang, B.; Li, W.; Xiang, Y.; Peng, X.; Ming, J.; Wu, X.; Zhang, Y.; Xu, Q. Allelic reprogramming of the histone modification H3K4me3 in early mammalian development. Nature 2016, 537, 553. [CrossRef]

26. Chen, F.; Fu, Q.; Pu, L.; Zhang, P.; Huang, Y.; Hou, Z.; Xu, Z.; Chen, D.; Huang, F.; Deng, T. Integrated analysis of quantitative proteome and transcriptional profiles reveals the dynamic function of maternally expressed proteins after parthenogenetic activation of buffalo oocyte. Mol. Cell. Proteom. 2018, 17, 1875-1891. [CrossRef]

27. Fu, Q.; Huang, Y.; Wang, Z.; Chen, F.; Huang, D.; Lu, Y.; Liang, X.; Zhang, M. Proteome profile and quantitative proteomic analysis of buffalo (Bubalus bubalis) follicular fluid during follicle development. Int. J. Mol. Sci. 2016, 17, 618. [CrossRef]

28. Memili, E.; Peddinti, D.; Shack, L.; Nanduri, B.; McCarthy, F.; Sagirkaya, H.; Burgess, S.C. Bovine germinal vesicle oocyte and cumulus cell proteomics. Reproduction 2007, 133, 1107-1120. [CrossRef]

29. Peddinti, D.; Memili, E.; Burgess, S.C. Proteomics-based systems biology modeling of bovine germinal vesicle stage oocyte and cumulus cell interaction. PLoS ONE 2010, 5, e11240. [CrossRef]

30. Deutsch, D.R.; Fröhlich, T.; Otte, K.A.; Beck, A.; Habermann, F.A.; Wolf, E.; Arnold, G.J. Stage-Specific proteome signatures in early bovine embryo development. J. Proteome Res. 2014, 13, 4363-4376. [CrossRef]

31. Ma, M.; Guo, X.; Wang, F.; Zhao, C.; Liu, Z.; Shi, Z.; Wang, Y.; Zhang, P.; Zhang, K.; Wang, N. Protein expression profile of the mouse metaphase-II oocyte. J. Proteome Res. 2008, 7, 4821-4830. [CrossRef]

32. Vitale, A.M.; Calvert, M.E.K.; Mallavarapu, M.; Yurttas, P.; Perlin, J.; Herr, J.; Coonrod, S. Proteomic profiling of murine oocyte maturation. Mol. Reprod. Dev. 2007, 74, 608-616. [CrossRef] [PubMed]

33. Zhang, P.; Ni, X.; Guo, Y.; Guo, X.; Wang, Y.; Zhou, Z.; Huo, R.; Sha, J. Proteomic-Based identification of maternal proteins in mature mouse oocytes. BMC Genom. 2009, 10, 348. [CrossRef]

34. Wang, S.; Kou, Z.; Jing, Z.; Zhang, Y.; Guo, X.; Dong, M.; Wilmut, I.; Gao, S. Proteome of mouse oocytes at different developmental stages. Proc. Natl. Acad. Sci. USA 2010, 107, 17639-17644. [CrossRef] [PubMed]

35. Pfeiffer, M.J.; Siatkowski, M.; Paudel, Y.; Balbach, S.T.; Baeumer, N.; Crosetto, N.; Drexler, H.C.; Fuellen, G.; Boiani, M. Proteomic analysis of mouse oocytes reveals 28 candidate factors of the "reprogrammome". J. Proteome Res. 2011, 10, 2140-2153. [CrossRef] [PubMed]

36. Katz-Jaffe, M.G.; Linck, D.W.; Schoolcraft, W.B.; Gardner, D.K. A proteomic analysis of mammalian preimplantation embryonic development. Reproduction 2005, 130, 899-905. [CrossRef] [PubMed]

37. Kim, J.; Kim, J.-S.; Jeon, Y.-J.; Kim, D.-W.; Yang, T.-H.; Soh, Y.; Lee, H.K.; Choi, N.-J.; Park, S.-B.; Seo, K.S. Identification of maturation and protein synthesis related proteins from porcine oocytes during in vitro maturation. Proteome Sci. 2011, 9, 28. [CrossRef]

38. Ellederova, Z.; Halada, P.; Man, P.; Kubelka, M.; Motlik, J.; Kovarova, H. Protein patterns of pig oocytes during In Vitro maturation. Biol. Reprod. 2004, 71, 1533-1539. [CrossRef]

39. Susor, A.; Ellederova, Z.; Jelinkova, L.; Halada, P.; Kavan, D.; Kubelka, M.; Kovarova, H. Proteomic analysis of porcine oocytes during in vitro maturation reveals essential role for the ubiquitin C-terminal hydrolase-L1. Reproduction 2007, 134, 559-568. [CrossRef]

40. Powell, M.D.; Manandhar, G.; Spate, L.; Sutovsky, M.; Zimmerman, S.; Sachdev, S.C.; Hannink, M.; Prather, R.S.; Sutovsky, P. Discovery of putative oocyte quality markers by comparative ExacTag proteomics. J. Proteom. Clin. Appl. 2010, 4, 337-351. [CrossRef]

41. Thompson, A.; Schäfer, J.; Kuhn, K.; Kienle, S.; Schwarz, J.; Schmidt, G.; Neumann, T.; Hamon, C. Tandem mass tags: A novel quantification strategy for comparative analysis of complex protein mixtures by MS/MS. Anal. Chem. 2003, 75, 1895-1904. [CrossRef]

42. Bishop, D.W. Metabolic conditions within the oviduct of the rabbit. Int. J. Fertil. 1957, 2, 11.

43. Mastroianni, L.; Jones, R. Oxygen tension within the rabbit fallopian tube. Reproduction 1965, 9, 99-102. [CrossRef] [PubMed]

44. Ross, R.; Graves, C. $\mathrm{O}_{2}$ levels in female rabbit reproductive-tract. Proc. J. Anim. Sci. 1974, $39,994$.

45. Maas, D.H.; Storey, B.T.; Mastroianni, L., Jr. Oxygen tension in the oviduct of the rhesus monkey (Macaca mulatta). Fertil. Steril. 1976, 27, 1312-1317. [CrossRef] 
46. Kasterstein, E.; Strassburger, D.; Komarovsky, D.; Bern, O.; Komsky, A.; Raziel, A.; Friedler, S.; Ron-El, R. The effect of two distinct levels of oxygen concentration on embryo development in a sibling oocyte study. J. Assist. Reprod. Genet. 2013, 30, 1073-1079. [CrossRef] [PubMed]

47. Wale, P.; Gardner, D. Time-Lapse analysis of mouse embryo development in oxygen gradients. Reprod. Biomed. Online 2010, 21, 402-410. [CrossRef]

48. Yuan, Y.; Van Soom, A.; Coopman, F.; Mintiens, K.; Boerjan, M.; Van Zeveren, A.; de Kruif, A.; Peelman, L. Influence of oxygen tension on apoptosis and hatching in bovine embryos cultured In Vitro. Theriogenology 2003, 59, 1585-1596. [CrossRef]

49. Stamati, K.; Mudera, V.; Cheema, U. Evolution of oxygen utilization in multicellular organisms and implications for cell signalling in tissue engineering. J. Tissue Eng. 2011, 2. [CrossRef]

50. Fatehi, A.N.; Roelen, B.A.; Colenbrander, B.; Schoevers, E.J.; Gadella, B.M.; Bevers, M.M.; Van Den Hurk, R. Presence of cumulus cells during in vitro fertilization protects the bovine oocyte against oxidative stress and improves first cleavage but does not affect further development. Zygote 2005, 13, 177-185. [CrossRef]

51. Basini, G.; Simona, B.; Santini, S.E.; Grasselli, F. Reactive oxygen species and anti-oxidant defences in swine follicular fluids. Reprod. Fertil. Dev. 2008, 20, 269-274. [CrossRef]

52. Mingoti, G.Z.; Castro, V.S.D.C.; Méo, S.C.; Barretto, L.S.S.; Garcia, J.M. The effects of macromolecular and serum supplements and oxygen tension during bovine In Vitro procedures on kinetics of oocyte maturation and embryo development. In Vitro Cell. Dev. Biol. Anim. 2011, 47, 361-367. [CrossRef] [PubMed]

53. Somfai, T.; Inaba, Y.; Aikawa, Y.; Ohtake, M.; Kobayashi, S.; Konishi, K.; Nagai, T.; Imai, K. Development of bovine embryos cultured in CR1aa and IVD101 media using different oxygen tensions and culture systems. Acta Vet. Hung. 2010, 58, 465-474. [CrossRef] [PubMed]

54. Liberti, M.V.; Locasale, J.W. The Warburg effect: How does it benefit cancer cells? Trends Biochem. Sci. 2016, 41, 211-218. [CrossRef] [PubMed]

55. Pantaleon, M.; Harvey, M.; Pascoe, W.; James, D.; Kaye, P. Glucose transporter GLUT3: Ontogeny, targeting, and role in the mouse blastocyst. Proc. Natl. Acad. Sci. USA 1997, 94, 3795-3800. [CrossRef]

56. Gardner, D.K.; Lane, M.; Stevens, J.; Schoolcraft, W.B. Noninvasive assessment of human embryo nutrient consumption as a measure of developmental potential. Fertil. Steril. 2001, 76, 1175-1180. [CrossRef]

57. Gardner, D.K.; Leese, H.J. Assessment of embryo viability prior to transfer by the noninvasive measurement of glucose uptake. J. Exp. Zool. 1987, 242, 103-105. [CrossRef]

58. Christofk, H.R.; Vander Heiden, M.G.; Harris, M.H.; Ramanathan, A.; Gerszten, R.E.; Wei, R.; Fleming, M.D.; Schreiber, S.L.; Cantley, L.C. The M2 splice isoform of pyruvate kinase is important for cancer metabolism and tumour growth. Nature 2008, 452, 230-233. [CrossRef]

59. Lunt, S.Y.; Muralidhar, V.; Hosios, A.M.; Israelsen, W.J.; Gui, D.Y.; Newhouse, L.; Ogrodzinski, M.; Hecht, V.; $\mathrm{Xu}, \mathrm{K}$.; Acevedo, P.N.M. Pyruvate kinase isoform expression alters nucleotide synthesis to impact cell proliferation. Mol. Cell 2015, 57, 95-107. [CrossRef]

60. Vander Heiden, M.G.; DeBerardinis, R.J. Understanding the intersections between metabolism and cancer biology. Cell 2017, 168, 657-669. [CrossRef]

61. Krisher, R.L.; Prather, R.S. A role for the Warburg effect in preimplantation embryo development: Metabolic modification to support rapid cell proliferation. Mol. Reprod. Dev. 2012, 79, 311-320. [CrossRef]

62. Gasparrini, B.J.T. In Vitro embryo production in buffalo species: State of the art. Theriogenology 2002, 57, 237-256. [CrossRef]

63. Verma, M.; Pandey, S.; Bhat, I.A.; Mukesh, B.; Anand, J.; Chandra, V.; Sharma, G.T. Impact of 1-carnitine on lipid content and post thaw survivability of buffalo embryos produced In Vitro. Cryobiology 2018, 82, 99-105. [CrossRef] [PubMed]

64. Nicholas, F. Genetic improvement through reproductive technology. Anim. Reprod. Sci. 1996, 42, $205-214$. [CrossRef]

65. Rizos, D.; Ward, F.; Duffy, P.; Boland, M.P.; Lonergan, P. Consequences of bovine oocyte maturation, fertilization or early embryo development In Vitro versus In Vivo: Implications for blastocyst yield and blastocyst quality. Mol. Reprod. Dev. 2002, 61, 234-248. [CrossRef]

66. Pereira, R.; Marques, C. Animal oocyte and embryo cryopreservation. Cell Tissue Bank. 2008, 9, $267-277$. [CrossRef]

67. Arav, A.; Zeron, Y.; Leslie, S.; Behboodi, E.; Anderson, G.B.; Crowe, J.H. Phase transition temperature and chilling sensitivity of bovine oocytes. Cryobiology 1996, 33, 589-599. [CrossRef] 
68. Seidel, G.E., Jr. Modifying oocytes and embryos to improve their cryopreservation. Theriogenology 2006, 65, 228-235. [CrossRef]

69. Rasmussen, T.P. Genomic medicine and lipid metabolism: LDL targets and stem cell research approaches. In Translational Cardiometabolic Genomic Medicine; Elsevier: Amsterdam, The Netherlands, 2016; pp. 99-118.

70. Merilainen, G.; Poikela, V.; Kursula, P.; Wierenga, R.K. The thiolase reaction mechanism: The importance of Asn316 and His348 for stabilizing the enolate intermediate of the Claisen condensation. Biochemistry 2009, 48, 11011-11025. [CrossRef]

71. Küch, E.-M.; Vellaramkalayil, R.; Zhang, I.; Lehnen, D.; Brügger, B.; Stremmel, W.; Ehehalt, R.; Poppelreuther, M.; Füllekrug, J. Differentially localized acyl-CoA synthetase 4 isoenzymes mediate the metabolic channeling of fatty acids towards phosphatidylinositol. Biochim. Biophys. Acta Mol. Cell Biol. Lipids 2014, 1841, 227-239. [CrossRef]

72. Hughes, C.S.; Moggridge, S.; Müller, T.; Sorensen, P.H.; Morin, G.B.; Krijgsveld, J. Single-pot, solid-phase-enhanced sample preparation for proteomics experiments. Nat. Protoc. 2019, 14, 68-85. [CrossRef]

73. Su, W.; Sun, J.; Shimizu, K.; Kadota, K. TCC-GUI: A shiny-based application for differential expression analysis of RNA-Seq count data. BMC Res. Notes 2019, 12, 133. [CrossRef] [PubMed]

74. Pavani, K.C.; Baron, E.E.; Faheem, M.; Chaveiro, A.; Da Silva, F.M. Optimisation of total RNA extraction from bovine oocytes and embryos for gene expression studies and effects of cryoprotectants on total RNA extraction. Cytol. Genet. 2015, 49, 232-239. [CrossRef]

75. Sood, T.J.; Lagah, S.V.; Sharma, A.; Singla, S.K.; Mukesh, M.; Chauhan, M.S.; Manik, R.; Palta, P. Selection of suitable internal control genes for accurate normalization of real-time quantitative PCR data of buffalo (Bubalus bubalis) blastocysts produced by SCNT and IVF. Cell. Reprogram. 2017, 19, 302-310. [CrossRef] [PubMed]

76. Livak, K.J.; Schmittgen, T.D. Analysis of relative gene expression data using real-time quantitative PCR and the 2- $\Delta \Delta \mathrm{CT}$ method. Methods 2001, 25, 402-408. [CrossRef] [PubMed] 